\title{
Two-Dimensional Neutronic and Fuel Cycle Analysis of the Transatomic Power Molten Salt Reactor
}

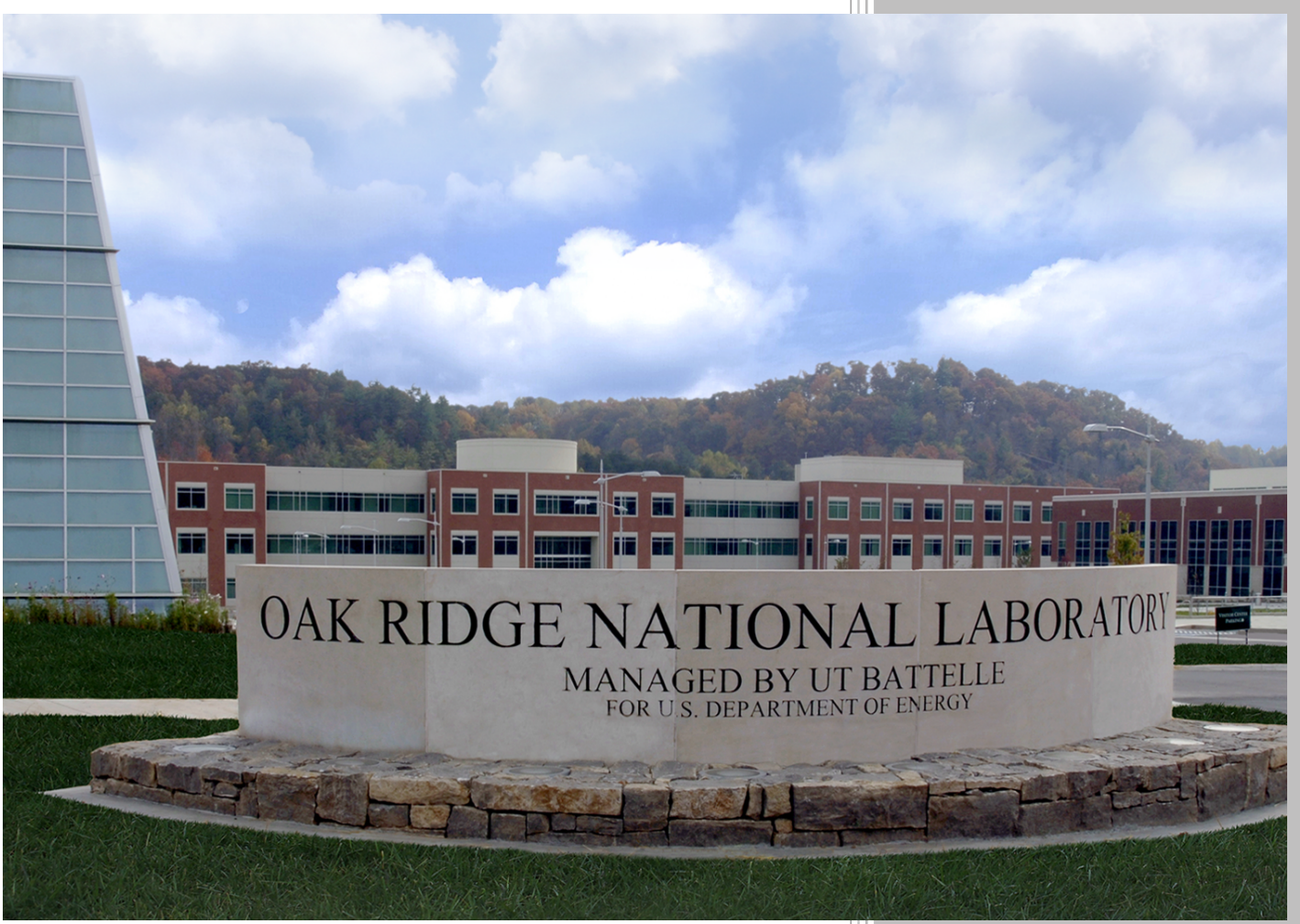

Approved for public release. Distribution is unlimited.

Benjamin R. Betzler, ORNL Jeffrey J. Powers, ORNL Andrew Worrall, ORNL Sean Robertson, TAP Leslie Dewan, TAP Mark Massie, TAP

January 15, 2017 


\title{
DOCUMENT AVAILABILITY
}

Reports produced after January 1, 1996, are generally available free via US Department of Energy (DOE) SciTech Connect.

Website: http://www.osti.gov/scitech/

Reports produced before January 1, 1996, may be purchased by members of the public from the following source:

\author{
National Technical Information Service \\ 5285 Port Royal Road \\ Springfield, VA 22161 \\ Telephone: 703-605-6000 (1-800-553-6847) \\ TDD: $703-487-4639$ \\ Fax: 703-605-6900 \\ E-mail: info@ntis.gov \\ Website: http://www.ntis.gov/help/ordermethods.aspx
}

Reports are available to DOE employees, DOE contractors, Energy Technology Data Exchange representatives, and International Nuclear Information System representatives from the following source:

Office of Scientific and Technical Information

PO Box 62

Oak Ridge, TN 37831

Telephone: $865-576-8401$

Fax: 865-576-5728

E-mail: reports@osti.gov

Website: http://www.osti.gov/contact.html

This report was prepared as an account of work sponsored by an agency of the United States Government. Neither the United States Government nor any agency thereof, nor any of their employees, makes any warranty, express or implied, or assumes any legal liability or responsibility for the accuracy, completeness, or usefulness of any information, apparatus, product, or process disclosed, or represents that its use would not infringe privately owned rights. Reference herein to any specific commercial product, process, or service by trade name, trademark, manufacturer, or otherwise, does not necessarily constitute or imply its endorsement, recommendation, or favoring by the United States Government or any agency thereof. The views and opinions of authors expressed herein do not necessarily state or reflect those of the United States Government or any agency thereof. 
Reactor and Nuclear Systems Division

\title{
TWO-DIMENSIONAL NEUTRONIC AND FUEL CYCLE ANALYSIS OF THE TRANSATOMIC POWER MOLTEN SALT REACTOR
}

\author{
Benjamin R. Betzler, Oak Ridge National Laboratory \\ Jeffrey J. Powers, Oak Ridge National Laboratory \\ Andrew Worrall, Oak Ridge National Laboratory \\ Sean Robertson, Transatomic Power Corporation \\ Leslie Dewan, Transatomic Power Corporation \\ Mark Massie, Transatomic Power Corporation
}

January 2017

\author{
Prepared by \\ OAK RIDGE NATIONAL LABORATORY \\ P.O. Box 2008 \\ Oak Ridge, Tennessee 37831-6285 \\ managed by \\ UT-Battelle, LLC \\ for the \\ US DEPARTMENT OF ENERGY \\ under contract DE-AC05-00OR22725
}





\section{CONTENTS}

Page

LIST OF FIGURES $\ldots \ldots \ldots \ldots \ldots \ldots \ldots \ldots \ldots \ldots \ldots$

LIST OF TABLES $\ldots \ldots \ldots \ldots \ldots \ldots \ldots \ldots$ vii

ABBREVIATIONS, ACRONYMS, and INITIALISMS . . . . . . . . . . . . . . ix

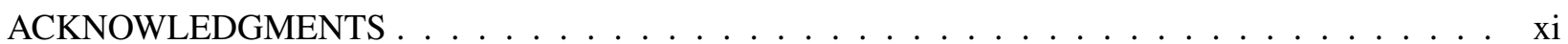

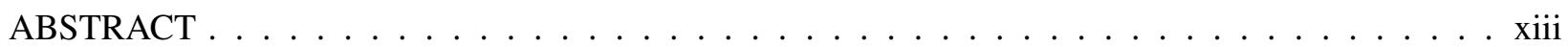

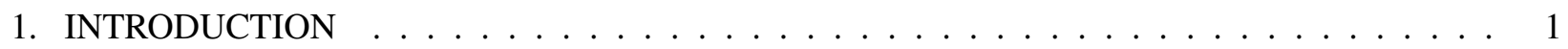

2. DESCRIPTION OF THE TRANSATOMIC POWER REACTOR . . . . . . . . . . . . . . 3

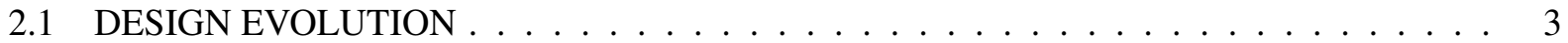

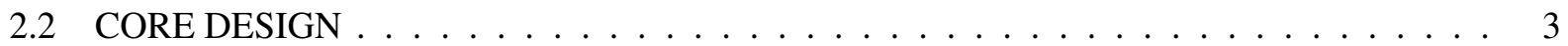

2.3 FUEL CYCLE CLASSIFICATION AND PERFORMANCE . . . . . . . . . . . . . . . . . 4

3. COMPUTATIONAL METHODS AND MODELS . . . . . . . . . . . . . . . . 7

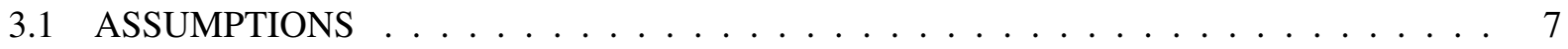

3.2 MODELING AND SIMULATION $\ldots \ldots \ldots \ldots \ldots \ldots$

3.3 MATERIAL REMOVAL AND FEEDS $\ldots \ldots \ldots \ldots \ldots$

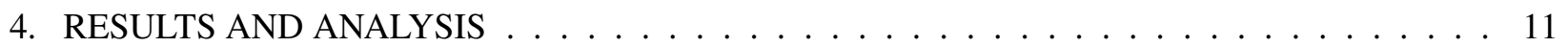

4.1 SIMULATION USING TAP-PROVIDED SPECIFICATIONS $\ldots \ldots \ldots \ldots \ldots$

4.2 TIME STEP REFINEMENT $\ldots \ldots \ldots \ldots \ldots \ldots \ldots$

4.3 FUEL FEED MASS AND ENRICHMENT $\ldots \ldots \ldots \ldots \ldots \ldots \ldots$

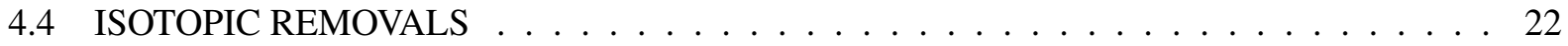

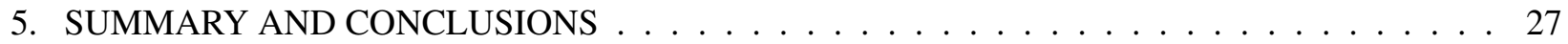

6. REFERENCES . . . . . . . . . . . . . . . . . . . . . . . . . . . 29 



\section{LIST OF FIGURES}

Figures $\quad$ Page

1 TAP MSR schematic showing movable moderator rod bundles and reactivity control. . . . . 4

2 Example of the 2D geometry used in SCALE/NEWT showing the progression of the pitch in the unit cell model as moderator rods are inserted into the core. . . . . . . . . . . . . 7

3 The TAP-provided leakage as a function of SVF (i.e., moderator rod insertion). $\ldots \ldots \ldots$

4 Comparison of ChemTriton-calculated $k$ eigenvalues during operation using the pre-determined SVF provided by TAP and the critical search function. . . . . . . . . . . . . . . 11

5 Comparison between the pre-determined time-dependent SVF and that obtained from the critical search calculation. . . . . . . . . . . . . . . . . . 12

6 ChemTriton-calculated spectral shift during operation using the critical search function. . . 13

7 ChemTriton-calculated uranium isotopic salt content during operation using the critical search function. . . . . . . . . . . . . . . . . . . . . . . . . 14

8 ChemTriton-calculated fissile and non-fissile plutonium salt content during operation using the critical search function. . . . . . . . . . . . . . . . . . . . 14

9 ChemTriton-calculated plutonium isotopic salt content during operation using the critical search function. . . . . . . . . . . . . . . . . . . . . . 15

10 ChemTriton-calculated fuel salt molar concentrations of uranium and actinides during operation using the critical search function. . . . . . . . . . . . . . . . . 16

11 ChemTriton-calculated $k$ eigenvalues during operation using the TAP-calculated pre-determined SVF and different depletion time step sizes. . . . . . . . . . . . . . . . . 16

12 ChemTriton-calculated ${ }^{235} \mathrm{U}$ content during operation using the TAP-calculated pre-determined

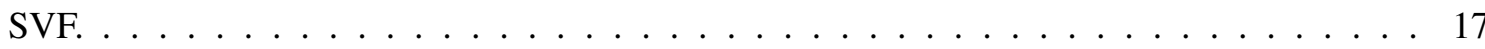

13 ChemTriton-calculated ${ }^{239} \mathrm{Pu}$ content during operation using the TAP-calculated pre-determined SVF . . . . . . . . . . . . . . . . . . . . . . 17

14 ChemTriton-calculated $k$ eigenvalues during operation using the critical search function for various enrichments of the feed material. . . . . . . . . . . . . . . . . . 19

15 ChemTriton-calculated SVF during operation using the critical search functions for various enrichments of the feed material.

16 ChemTriton-calculated fissile plutonium mass during operation for various enrichments of the feed material. . . . . . . . . . . . . . . . . . . . 20

17 ChemTriton-calculated $k$ eigenvalues during operation for various feed material rates. . . . 20

18 ChemTriton-calculated SVF during operation using the critical search functions for various feed material rates. . . . . . . . . . . . . . . . . . . . . . . 21

19 ChemTriton-calculated fissile plutonium mass during operation for various feed material

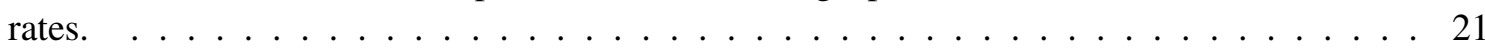

20 ChemTriton-calculated fuel salt molar concentrations of uranium for various feed material

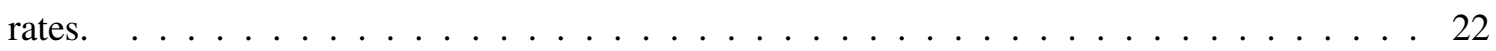

21 ChemTriton-calculated fuel salt molar concentrations of actinides for various feed material

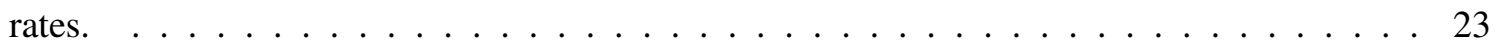

22 ChemTriton-calculated core EOL for various enrichments and rates of feed materials. . . . 23

23 ChemTriton-calculated discharge burnup for various enrichments and rates of feed materials. 24

24 Comparison of ChemTriton-calculated $k$ eigenvalues during operation using the critical search function for various cycle times for rare earth elements. . . . . . . . . . . . 25 
25 ChemTriton-calculated core EOL and discharge burnup for various cycle times for rare earth elements. . . . . . . . . . . . . . . . . . . . 25 


\section{LIST OF TABLES}

Tables $\quad$ Page

1 Cycle times of elements removed from fuel salt . . . . . . . . . . . . . . . 9

2 Normalized total fuel load and actinide waste from an LWR and the TAP reactor . . . . . . . 13 



\section{ABBREVIATIONS, ACRONYMS, and INITIALISMS}

1D one-dimensional

2D two-dimensional

3D three-dimensional

BOL beginning of life

DOE Department of Energy

E\&S Evaluation and Screening

EG evaluation group

EOL end of life

GAIN Gateway for Accelerated Innovation in Nuclear

GWd gigawatt days

LEU low-enriched uranium

LWR light-water reactor

MSR molten salt reactor

MSRE molten salt reactor experiment

MTU metric tons of uranium

MWt megawatts thermal

ORNL Oak Ridge National Laboratory

SNF spent nuclear fuel

SVF salt volume fraction

TAP Transatomic Power Corporation

TRU transuranic elements 



\section{ACKNOWLEDGMENTS}

Support for this work was provided by the US Department of Energy, Office of Nuclear Energy Gateway for Accelerated Innovation in Nuclear, Nuclear Energy Voucher program. 



\begin{abstract}
This status report presents the results from the first phase of the collaboration between Transatomic Power Corporation (TAP) and Oak Ridge National Laboratory (ORNL) to provide neutronic and fuel cycle analysis of the TAP core design through the Department of Energy Gateway for Accelerated Innovation in Nuclear, Nuclear Energy Voucher program. The TAP design is a molten salt reactor using movable moderator rods to shift the neutron spectrum in the core from mostly epithermal at beginning of life to thermal at end of life. Additional developments in the ChemTriton modeling and simulation tool provide the critical moderator-to-fuel ratio searches and time-dependent parameters necessary to simulate the continuously changing physics in this complex system. Results from simulations with these tools show agreement with TAP-calculated performance metrics for core lifetime, discharge burnup, and salt volume fraction, verifying the viability of reducing actinide waste production with this design. Additional analyses of time step sizes, mass feed rates and enrichments, and isotopic removals provide additional information to make informed design decisions. This work further demonstrates capabilities of ORNL modeling and simulation tools for analysis of molten salt reactor designs and strongly positions this effort for the upcoming three-dimensional core analysis.
\end{abstract}





\section{INTRODUCTION}

A recent Third Way report ${ }^{1}$ detailing $\$ 1.3$ billion in private investment in advanced reactor technology includes several liquid-fueled molten salt reactor (MSR) concepts. Interest in these MSR concepts is driven by the enhanced safety, economic, and promising fuel cycle benefits of these advanced reactor concepts. The Department of Energy (DOE) Office of Nuclear Energy established the Gateway for Accelerated Innovation in Nuclear (GAIN) to provide private companies pursuing innovative nuclear energy technologies with access to the technical support necessary to move toward commercialization. ${ }^{2}$

One of these GAIN small business voucher awards was to Transatomic Power Corporation (TAP) to work with Oak Ridge National Laboratory (ORNL) to perform neutronic and fuel cycle analysis and design of TAP's innovative MSR concept. The first phase of this project is to perform two-dimensional (2D) analysis with ORNL-developed tools to verify TAP-calculated metrics ${ }^{3,4}$ and develop an understanding of the effects of fuel feed and isotopic removal rates to prepare for the more complex three-dimensional (3D) analysis in coming phases. Design information was based on the TAP white papers ${ }^{3,4}$ wherever possible.

This report discusses the results of the first phase of this collaboration between ORNL and TAP and serves as a status report of the effort as a whole. Section 2 describes the TAP core design; Section 3 discusses the methods development in ChemTriton for simulating this design; Section 4 details the results from simulations; and Section 5 summarizes and gives closing remarks on future work. The design specifications and performance metrics provided in sections 2 and 3 are from the TAP white papers; ${ }^{3,4}$ this information is used for fuel cycle classification and elemental removal definitions (i.e., results from ORNL modeling and simulation tools are not incorporated in these sections). 



\section{DESCRIPTION OF THE TRANSATOMIC POWER REACTOR}

The TAP design is a 1250 MWt MSR with an LiF-based uranium fuel salt (Fig. 1). ${ }^{3}$ The primary difference between this design and previous similar MSRs is the use of movable zirconium hydride metal rods instead of graphite as a moderator. Neutronically, zirconium hydride moderates neutrons more efficiently than graphite; significantly less zirconium hydride (by volume) is necessary to achieve a thermal energy spectrum similar to that which a graphite moderator provides. In this section, the design characteristics and metrics used in fuel cycle classification are based on information presented in the TAP white papers., 3,4

\subsection{DESIGN EVOLUTION}

The TAP design is adapted from the original design of the Molten Salt Reactor Experiment ${ }^{5}$ (MSRE) by modifying two fundamental design features: the fuel salt and the moderator. Substitution of $\mathrm{LiF}_{\mathrm{U}} \mathrm{UF}_{4}$ for the MSRE's LiF-BeF $-\mathrm{ZrF}_{4}-\mathrm{UF}_{4}$ fuel salt provides for an increase in the uranium concentration within the fuel salt (from 0.9 to $27.5 \%$ ) while maintaining a relatively low melting point $\left(490^{\circ} \mathrm{C}\right.$ compared with $434^{\circ} \mathrm{C}$ ). Although graphite is an excellent moderator in terms of its capture cross-section and performs well with molten salts, the low lethargy gain per collision requires that large quantities be present to achieve criticality, making the core large and hindering the core power density. To resolve this issue, the TAP design forgoes a graphite moderator and uses clad zirconium hydride, allowing for a significant increase in power density. These two choices together ( $\mathrm{LiF}-\mathrm{UF}_{4}$ and zirconium hydride) allow for a more compact reactor than the original graphite design, facilitating the deployment of this technology in the current commercially available 5\% low-enriched uranium (LEU) based fuel cycle. Initial details of the TAP design ${ }^{6,7}$ were updated in July 2016 in a technical white paper $^{3}$ and a neutronics overview. ${ }^{4}$ All analyses and comparisons herein are based on the information available in the most recent open literature and additional information provided by TAP on the most recent iteration of its design.

\subsection{CORE DESIGN}

To account for the loss of fissile material over the course of a cycle of operation, solid-fueled nuclear reactors use core configurations and fuel compositions that result in excess positive reactivity at the beginning of life (BOL). Excess reactivity is controlled via soluble boron in the coolant, burnable absorbers, and/or control rods, which are gradually removed and/or depleted toward the end of life (EOL). This reactivity swing is inherently inefficient, as neutrons that could otherwise be used for fission and conversion in the fuel are effectively wasted in absorbers and control rods. The TAP design aims to eliminate this inefficiency through the use of continuous feeds, removal of fission products, and movable moderator rods, compensating for the buildup of negative reactivity through the continuous insertion of positive reactivity via increased moderation and material addition and removal. The design proposes to have several moderator rods moving continuously through drive mechanisms to provide short-time-scale control, maintaining reactivity in the long term by replacing stationary zirconium hydride assemblies with more highly populated arrays.

In the cylindrical TAP core, fuel salt flows around moderator assemblies consisting of arrays of movable small-diameter zirconium hydride rods clad in a corrosion-resistant material (Fig. 1). The moderator-to-fuel salt ratio, or salt volume fraction (SVF), in the core is varied during operation to shift the spectrum from intermediate to thermal energies (from BOL to EOL, respectively) to maximize the fuel burnup. An intermediate spectrum is defined as one in which the majority of fissions occur between $1 \mathrm{eV}$ 


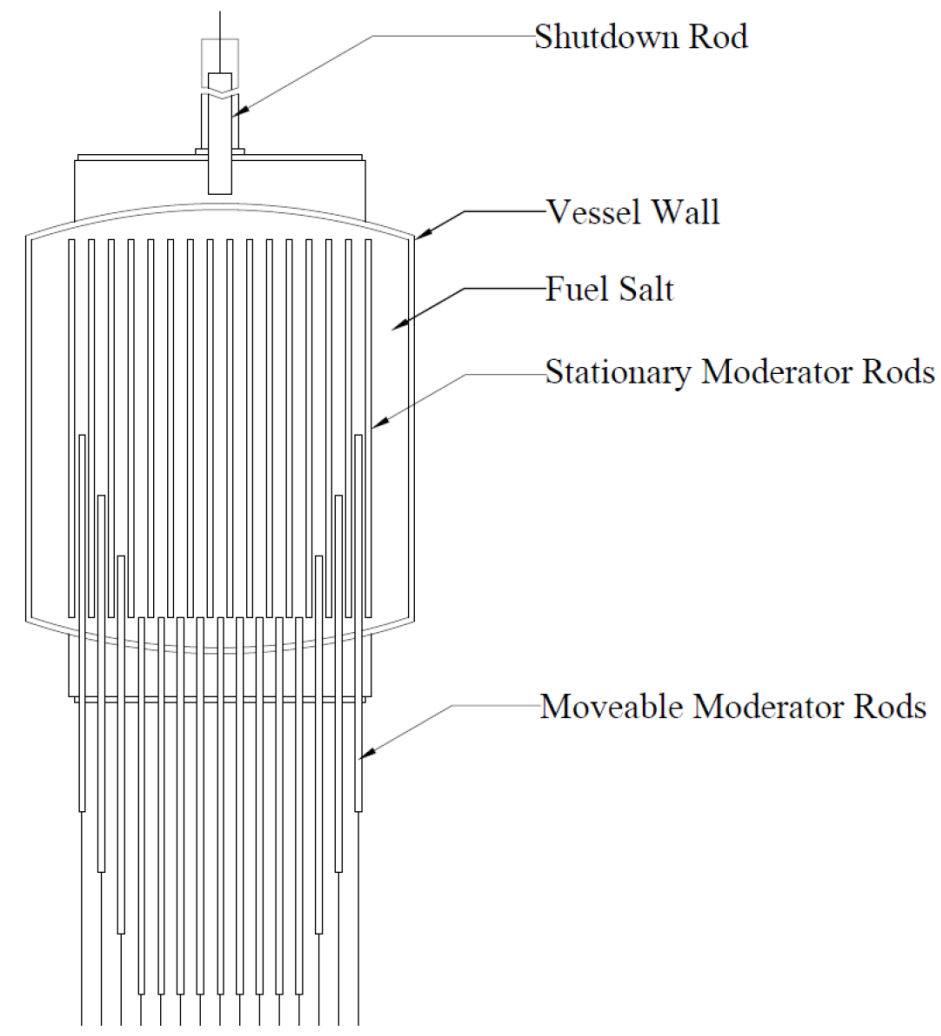

Fig. 1. TAP MSR schematic showing movable moderator rod bundles and reactivity control.

and $100 \mathrm{keV}$. Unmoderated salt flowing around the moderator assemblies provides for a potential reduction in flux at the vessel wall. Three fueling scenarios for the TAP design have been presented: ${ }^{4}$ (1) a 5\% LEU startup core with 5\% LEU online feed, (2) a 5\% LEU startup core with a light-water reactor spent nuclear fuel (LWR SNF) online feed, and (3) a 10\% LEU startup core with a 19.9\% LEU online feed. The primary focus has been the first fueling scenario utilizing near-term deployable 5\% LEU.

\subsection{FUEL CYCLE CLASSIFICATION AND PERFORMANCE}

A comprehensive Evaluation and Screening (E\&S) Study of nuclear fuel cycle options previously completed by $\mathrm{DOE}^{8}$ examined potential benefits and challenges of a large number of possible fuel cycle approaches by categorizing them into evaluation groups (EGs) based upon several types of characteristics. Assessing which EG the reference TAP reactor concept and fuel cycle approach would fall into provides worthwhile context and information regarding general attributes of the reactor and its fuel cycle.

The reference TAP design discussed and analyzed in this report uses a single-stage fuel cycle with a critical neutron economy, a fresh feed of LEU (5-19.9\% enriched), and a neutron energy spectrum that shifts from intermediate to thermal energies as moderator rods are inserted during reactor operation. The TAP design operates with an intermediate spectrum for the first $80 \%$ of its operating lifetime, after which the spectrum thermalizes significantly. Fuel is used to high burnup (up to $200 \mathrm{GWd} / \mathrm{MTU}$ ) to maximize waste reduction, and some fission products are separated from the fuel salt during operation to improve reactor performance. ${ }^{4}$ On the basis of these fuel cycle characteristics, the TAP design would be categorized as belonging to EG15 from the E\&S study. Note that EG15 is a limited-recycle EG; limited recycling of 
the TAP fuel is not performed in the traditional sense (i.e., recycling spent fuel once or a limited number of times before its disposal with high-level waste generated from the recycling processes). Additionally, EG15 is a multi-stage EG; the TAP design simply exhibits characteristics of two separate stages in a single physical system (albeit at different times). But owing to its online fission product separations and intermediate-to-thermal spectral shift, the fuel cycle performance of the TAP design is expected to be similar to that of multi-stage fuel cycles with limited recycling classified as EG15. ${ }^{8}$

Alternate fuels are discussed in TAP design descriptions. An alternate fueling scenario starts the core up using LEU (5\% enrichment) and uses recycled uranium and transuranic elements (TRU) from LWR SNF as the only feed material during operation; with this continuous recycling of TRU, the TAP design would be categorized as EG32. ${ }^{4}$ Note that this is still considered a single-stage fuel cycle because the existing LWR SNF inventory is the source material in this scenario. Additionally, EG32 is a multi-stage EG; the TAP design is still categorized in this group for the reasons stated above. While the TAP design could potentially use thorium fuel, it is not incorporated in future alternate fueling scenarios. ${ }^{3}$

Previous work ${ }^{4}$ has shown that the TAP design outperforms traditional LWRs in waste metrics, with the TAP design generating 53-83\% less actinide waste per megawatt generated. With fueling scenarios 1 and 2, the TAP reactor achieves a burnup of over $80 \mathrm{GWd} / \mathrm{MTU}$ and a waste reduction of $53 \%$. With fueling scenario 3, the TAP reactor achieves a burnup of over $200 \mathrm{GWd} / \mathrm{MTU}$ and a waste reduction of $83 \%$. A typical LWR achieves a burnup of $45 \mathrm{GWd} / \mathrm{MTU}$ with enrichments of up to $5 \%$. 



\section{COMPUTATIONAL METHODS AND MODELS}

Results of the analysis of the TAP reactor were obtained primarily by using ChemTriton, ${ }^{9}$ a modeling and simulation tool developed for MSR analysis in which SCALE ${ }^{10}$ is used to perform the neutron transport and depletion calculations with the SCALE/TRITON ${ }^{11}$ module. This tool draws from previous efforts at ORNL in MSR modeling and simulation tool development ${ }^{12}$ and applications. ${ }^{13-16}$ The ChemTriton tool is designed to be a generic and flexible tool for performing fuel cycle analysis and simulating a variety of liquid-fueled systems.

\subsection{ASSUMPTIONS}

The two main challenges for modeling and simulation of liquid-fueled systems are (1) the flowing fuel material and (2) the ongoing separations or feeds of material during operation.

Precursor drift in flowing fuel affects depletion calculations by augmenting the energy spectrum and strength of the neutron source within the core. Accounting for this drift requires a correction factor or the addition of a convection term to the neutron transport equation. ${ }^{17}$ ChemTriton does not currently account for delayed neutron precursor drift and focuses on simulating online separations and feeds. The effect of this drift on the calculated $k$ eigenvalue is less than a few hundred pcm. It is assumed that, for eigenvalue calculations being performed to establish the core lifetime of a conceptual core design, the effects of precursor drift on the results are minimal and thus precursor drift can reasonably be neglected.

SCALE/TRITON does not allow the specification of non-zero removal or feed rates for depletion simulations, though the ORIGEN ${ }^{18}$ input allows for the specification of these rates. For ORIGEN, these rates must be expressed in terms of a decay constant, and an accurate removal/feed rate must take into account liquid fuel flow rates and reactor design. Instead of using this approach, ChemTriton uses a semi-continuous batch process to simulate the continuous process. It is assumed that this semi-continuous approach is able to provide sufficient fidelity for this effort.

To reduce computational burdens, the parametric studies and analysis herein use a 2D unit cell representation of the TAP reactor solved with the transport module NEWT. ${ }^{11}$ This representation includes a moderator pin and the fuel salt material (Fig. 2). The important quantity in these ChemTriton calculations

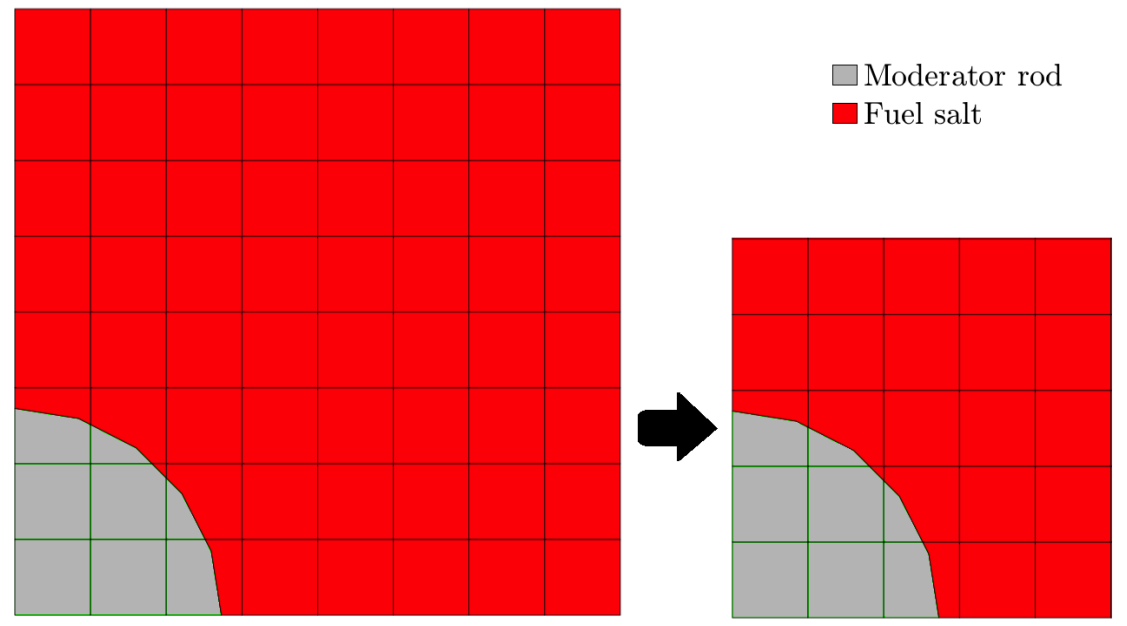

Fig. 2. Example of the 2D geometry used in SCALE/NEWT showing the progression of the pitch in the unit cell model as moderator rods are inserted into the core. 
is the spectrum in the fuel salt material used to deplete the fuel. Although the spectrum in the fuel salt may vary throughout the core, the single fuel salt is considered well-mixed; depleting the material with a single core-averaged spectrum is a reasonable approximation. It is assumed that this simple unit cell model generates a sufficiently accurate approximation of this core-averaged spectrum.

\subsection{MODELING AND SIMULATION}

Capabilities were added to ChemTriton to provide the necessary features to simulate a system with a changing moderator-to-fuel ratio. ChemTriton was given access to the moderator pin radius and pin pitch, allowing it to change these parameters during a calculation (Fig. 2). In addition, a moderator-to-fuel ratio critical search function was developed to vary the moderator pin radius or pin pitch during the calculation to satisfy a given time-dependent criticality condition. This critical search function uses a one-dimensional (1D) model with the 56-group ENDF/B-VII. $1^{19}$ cross section library to reduce calculation times. A small correction factor was included to reduce the bias between this reduced model and the full 2D model using 252-group ENDF-B/VII.1 cross sections. The results and analysis shown herein use the pin pitch critical search function because it more accurately represents the physical system (i.e., it maintains the size of the moderator pins).

As a result of the shift in the spectrum during operation, the amount of neutron leakage for the TAP reactor changes throughout operation (e.g., leakage is greater with a harder spectrum). The simplified transport model used for the analysis does not incorporate leakage; the $k$ eigenvalue of the unit cell must be higher than 1.0 to account for the leakage. This leakage is a function of the spectrum, which is dependent on the number of moderator rods inserted into the core. ${ }^{4}$ For use during the critical search in ChemTriton, the TAP-calculated leakage correlation is converted to a function of SVF (Fig. 3).

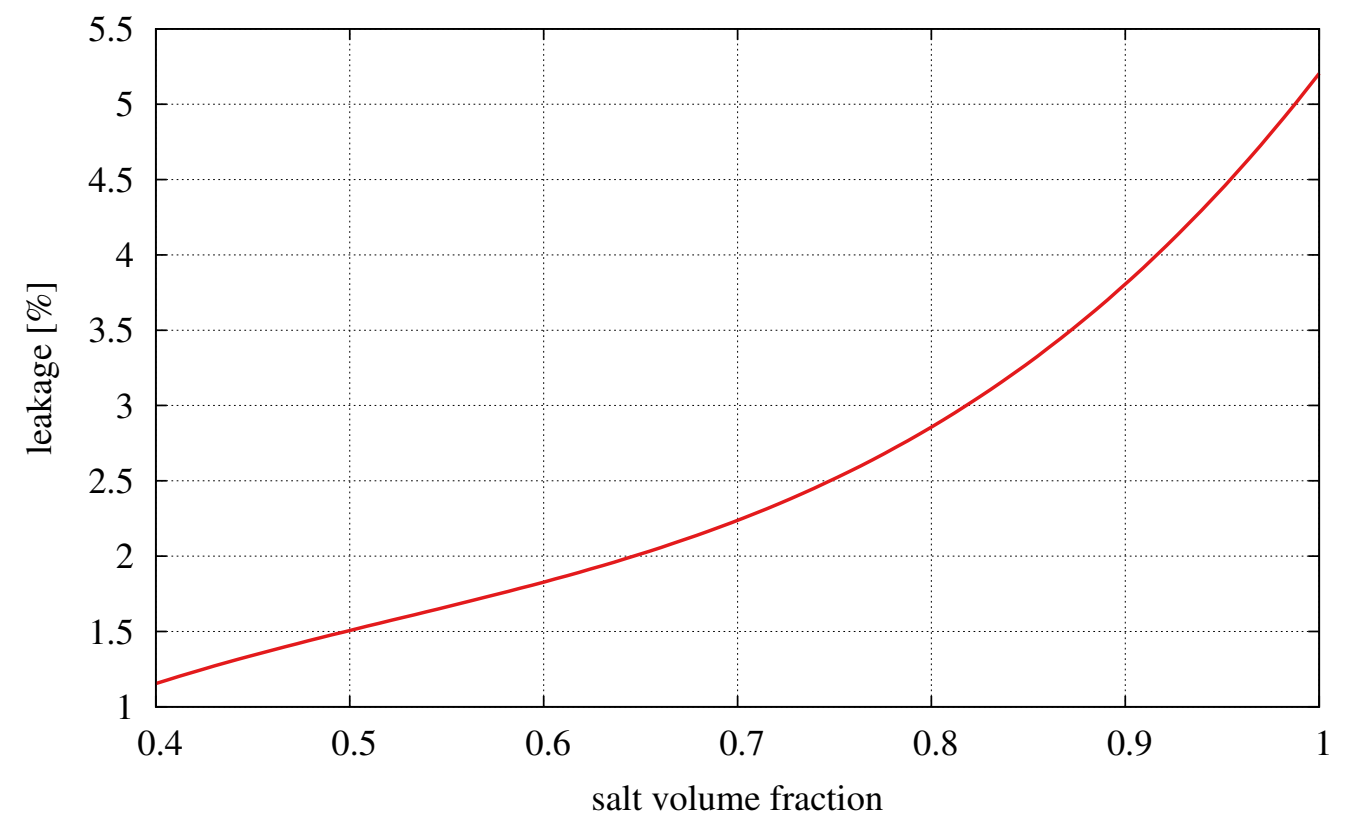

Fig. 3. The TAP-provided leakage as a function of SVF (i.e., moderator rod insertion). 


\subsection{MATERIAL REMOVAL AND FEEDS}

ChemTriton has the ability to simulate time-dependent material feed and removal rates. This capability is useful in studying the effects of the feed or separation of specific elements within the fuel salt, which is unique to liquid-fueled reactors. In solid-fueled reactors, the fission products that build up during operation remain within the fuel and negatively impact core reactivity. A potential benefit of liquid-fueled systems is that fission products that significantly affect core reactivity may be separated during operation, potentially reducing fuel consumption and increasing fuel utilization. To reduce radioactive material handling, some MSR designs separate only the fission products that are insoluble, physically plate out on cold surfaces (passive removal), or cause other salt chemistry or corrosion issues.

In previous work, ${ }^{16}$ salt treatments were defined as necessary because of chemistry issues, and salt processing was defined as a reactor performance enhancement. Elements were placed into several processing groups: volatile gases, noble metals, seminoble metals, volatile fluorides, rare earth elements, and discard (Table 1). Each element was assigned a characteristic cycle time, defined as the time required for the full removal of a given element.

The design of the TAP reactor specifies additional elements that are removed during operation. In addition, the removal rates of these elements are specified in units of number per second. These elements are categorized into the previously defined processing groups (Table 1), but the removal rates of most of these elements (i.e., all except for hydrogen) are very low.

Table 1. Cycle times of elements removed from fuel salt

\begin{tabular}{lll}
\hline Processing group & Elements & Cycle time \\
\hline \multicolumn{2}{c}{ Elements removed in previous work $^{16}$} & \\
Volatile gases & $\mathrm{Xe}, \mathrm{Kr}$ & $20 \mathrm{~s}$ \\
Noble metals & $\mathrm{Se}, \mathrm{Nb}, \mathrm{Mo}, \mathrm{Tc}, \mathrm{Ru}, \mathrm{Rh}, \mathrm{Pd}, \mathrm{Ag}, \mathrm{Sb}, \mathrm{Te}$ & $20 \mathrm{~s}$ \\
Seminoble metals & $\mathrm{Zr}, \mathrm{Cd}, \mathrm{In}, \mathrm{Sn}$ & 200 days \\
Volatile fluorides & $\mathrm{Br}, \mathrm{I}$ & 60 days \\
Rare earth elements & $\mathrm{Y}, \mathrm{La}, \mathrm{Ce}, \mathrm{Pr}, \mathrm{Nd}, \mathrm{Pm}, \mathrm{Sm}, \mathrm{Gd}$ & 50 days \\
& $\mathrm{Eu}$ & 500 days \\
Discard & $\mathrm{Rb}, \mathrm{Sr}, \mathrm{Cs}, \mathrm{Ba}$ & 3435 days \\
\multicolumn{1}{c}{ Additional elements removed } \\
Volatile gases & $\mathrm{H}$ & \\
Noble metals & $\mathrm{Ti}, \mathrm{V}, \mathrm{Cr}, \mathrm{Cu}$ & $20 \mathrm{~s}$ \\
Seminoble metals & $\mathrm{Mn}, \mathrm{Fe}, \mathrm{Co}, \mathrm{Ni}, \mathrm{Zn}, \mathrm{Ga}, \mathrm{Ge}, \mathrm{As}$ & 3435 days \\
Rare earth elements & $\mathrm{Sc}$ & 3435 days \\
Discard & $\mathrm{Ca}$ & 3435 days \\
\hline
\end{tabular}

${ }^{(a)}$ As specified in the TAP design. ${ }^{4}$ 



\section{RESULTS AND ANALYSIS}

Initial analysis of the TAP design using only information in the open literature ${ }^{3,4}$ supported the TAP-calculated waste reduction and fuel cycle metrics and determined the feasibility of the overall design. Fuel cycle benefits are realized via the longer operation time of the TAP design for a given amount of loaded fuel, driven by the spectral shift approach employed to maximize fuel burnup and the conversion of ${ }^{238} \mathrm{U}$ to fissile ${ }^{239} \mathrm{Pu}$. The overall reactor design is feasible neutronically, but the assessments have been limited to 2D and do not address some challenges that are expected with modeling in 3D (e.g., axial power shaping with moderator rods inserted from bottom of core). For the analysis herein, additional TAP information omitted from the open literature improves ORNL predictive models to enable better agreement with TAP calculations. This analysis focuses on the primary fueling scenario of the TAP reactor, in which the reactor is initially loaded and continuously fueled with 5\% LEU. Trends identified during the analysis with this fueling scenario are applied and extended to estimate the performance of the TAP reactor using the alternate fueling scenarios. This extension is completed without additional ChemTriton calculations.

\subsection{SIMULATION USING TAP-PROVIDED SPECIFICATIONS}

ChemTriton simulations using the TAP-calculated time-dependent $\mathrm{SVF}^{4}$ and the critical search function differ slightly for the time-dependent calculated $k$ eigenvalues (Fig. 4). This difference is expected, as the TAP-calculated SVF is determined using an assembly-level Monte Carlo neutronics model with a batch (i.e., non-continuous) SVF modification and some slightly different design parameters (e.g., moderator rod cladding). Models using continuously inserted rods are in better agreement with the

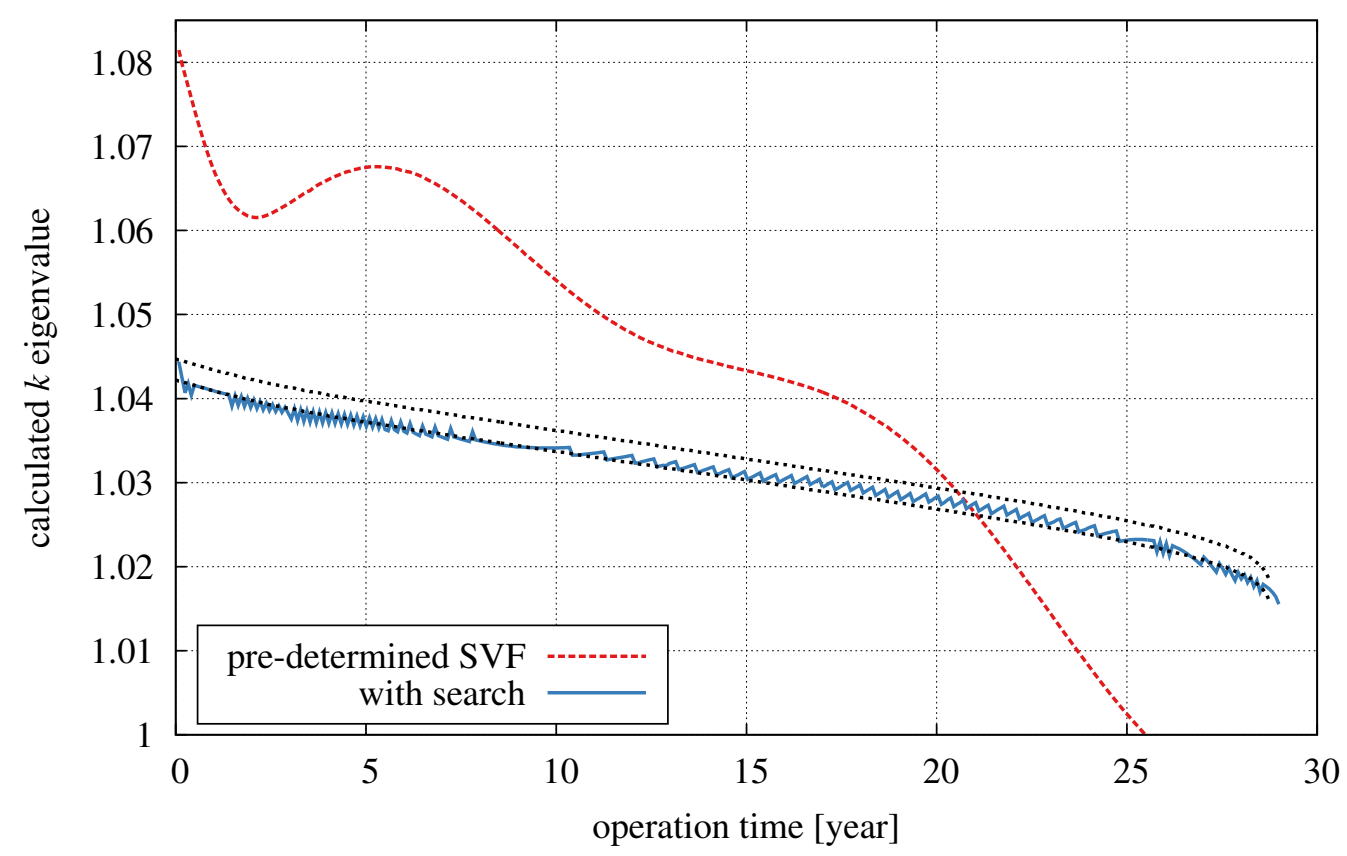

Fig. 4. Comparison of ChemTriton-calculated $k$ eigenvalues during operation using the pre-determined SVF provided by TAP and the critical search function. SVF is adjusted with a variable pitch and a fixed moderator rod diameter of $2.3 \mathrm{~cm}$. The dotted line shows the criticality condition range for the search. ChemTriton uses $30-$ day time steps in this calculation. 
ChemTriton-calculated SVF. The ChemTriton moderator-to-fuel ratio critical search routine performs well in this application, exhibiting small variations in the calculated $k$ due to the larger reactivity search range of $250 \mathrm{pcm}$. A constant $400 \mathrm{pcm}$ bias is applied to the criticality condition to reduce the difference between the 1D 56-group search calculation and the full 2D 252-group calculation.

A comparison of the pre-determined and ChemTriton-calculated time-dependent SVFs shows the sensitivity in the $k$ eigenvalue to a small change in the SVF (Fig. 5). The ChemTriton-calculated SVF decreases linearly over the first half of the core lifetime; after that, the insertion rate of moderator rods is increased to compensate for the change in the worth of the fission products and other absorbers that have built up in the fuel salt as a result of the spectral shift (Fig. 6). With respect to the pre-determined SVF, ChemTriton calculates a higher SVF during most of the reactor operation before decreasing quickly toward the end of the reactor lifetime. The ChemTriton-calculated SVF drops below the pre-determined SVF after 24 years of operation. This rapid decrease is caused by the depletion of the remaining fissile material and thermalization of the neutron spectrum. The worth of each moderator rod successively inserted into the core decreases as the core depletes. Additionally, the moderator rod radius was optimized for a LEU fuel, not a mixed plutonium-uranium fuel with a significant actinide content. The neutron spectrum changes very little during the first 15 years of reactor operation, before thermalizing rapidly toward EOL (Fig. 6).

Regardless of these differences, ChemTriton calculates metrics consistent with TAP-calculated metrics ${ }^{4}$ for operation lifetime and total burnup of the discharged fuel. ChemTriton calculates an operational lifetime of 29.0 years, after which the fuel achieves a burnup of $87.8 \mathrm{GWd} / \mathrm{MTU}$. The end of operational lifetime is considered as the time at which the minimum SVF is obtained, as restricted by the moderator assembly geometry (e.g., pitch, rod diameter, assembly pitch). The burnup is calculated using the total mass of uranium loaded into the core.

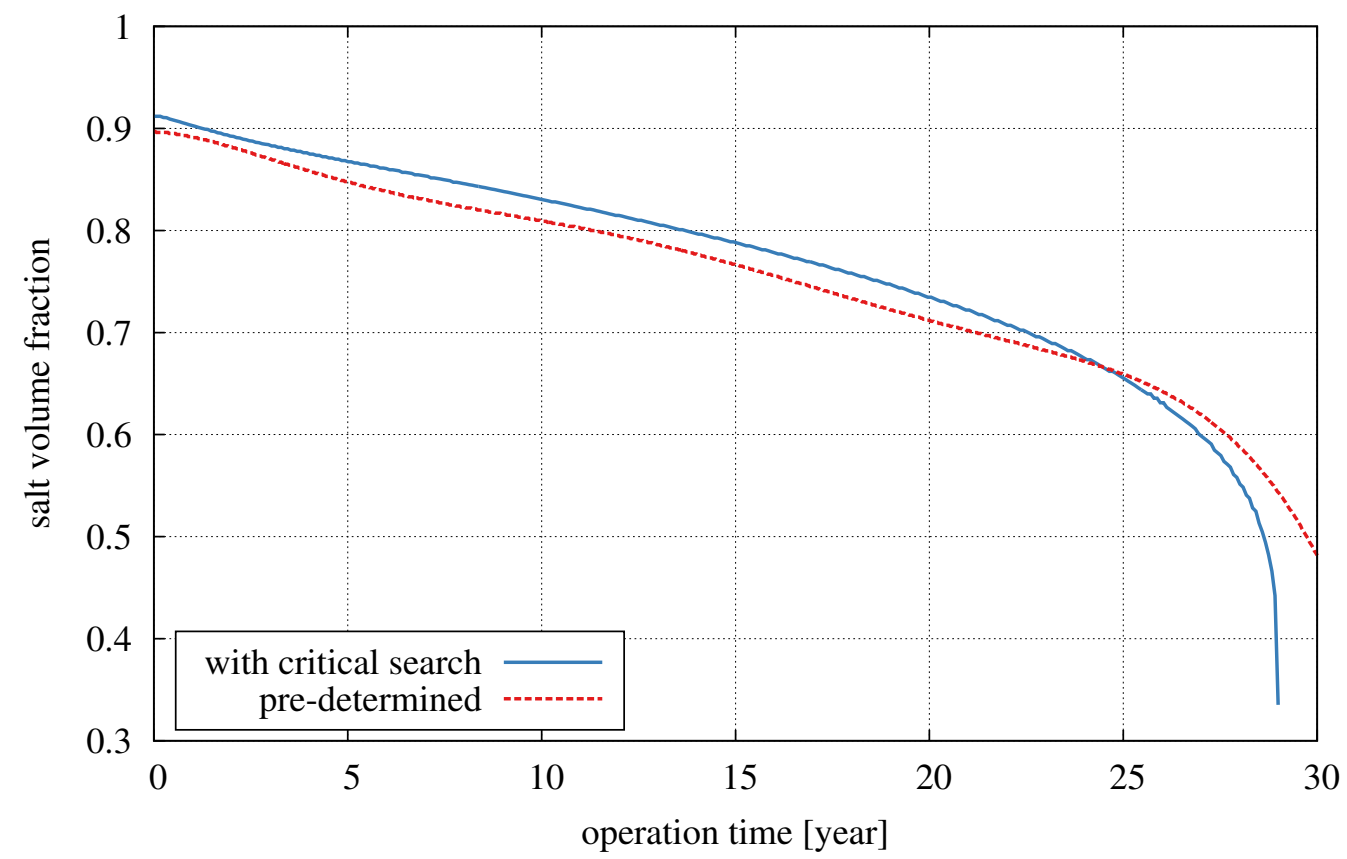

Fig. 5. Comparison between the pre-determined time-dependent SVF and that obtained from the critical search calculation. 
This high burnup is achievable because of the spectral shift in the TAP reactor design and online refueling of LEU. The LEU fuel that is continuously loaded into the TAP reactor is not sufficient to maintain the fissile material content in the core (Fig. 7), as the uranium enrichment continually decreases during operation and nears $0.69 \%$ at EOL. During the first 14 years of operation, the TAP reactor breeds fissile plutonium, peaking at a total fissile plutonium content of near 2.3 tons (Fig. 8). A significant amount of non-fissile plutonium builds up during operation and accounts for 55\% of the plutonium at EOL. This non-fissile plutonium negatively impacts criticality in the reactor. The majority of the fissile plutonium is ${ }^{239} \mathrm{Pu}$, though higher concentrations of ${ }^{241} \mathrm{Pu}$ are built up during operation (Fig. 9). The total ${ }^{239} \mathrm{Pu}$ in the core increases during the first 12 years of operation owing to the harder neutron spectrum. After 12 years, the more thermalized spectrum generates less ${ }^{239} \mathrm{Pu}$ as more of it is progressively burned.

Normalized per GWt-year, the TAP design requires only $57 \%$ of the fuel required by an LWR (Table 2). Additionally, the TAP design burns $4.2 \%$ more of its initial fuel load than an LWR. This results in a total actinide waste reduction of nearly 50\%. A similar waste reduction is expected when LWR SNF is used as the feed during operation. The actinide component of LWR SNF has a lower fissile material concentration than $5 \% \mathrm{LEU}$ and adds less fertile ${ }^{238} \mathrm{U}$ to the fuel salt, shortening the operation time of the

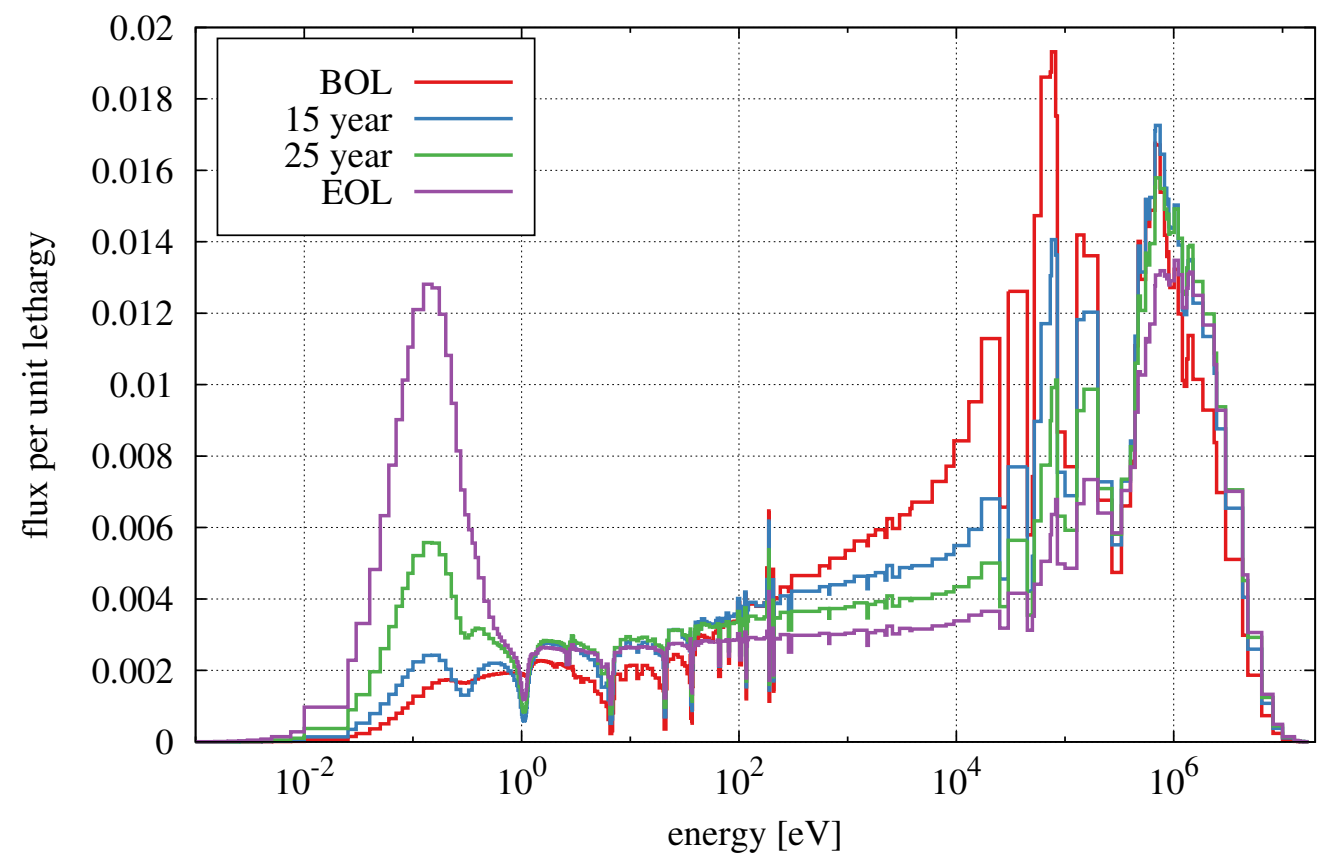

Fig. 6. ChemTriton-calculated spectral shift during operation using the critical search function.

Table 2. Normalized total fuel load and actinide waste from an LWR and the TAP reactor

\begin{tabular}{lll}
\hline Parameter & LWR $^{8}$ & TAP \\
\hline Loaded fuel [MT per GWt-year] & 7.31 & 4.16 \\
Waste [MT per GWt-year] & 6.92 & 3.77 \\
Resource utilization [\%] ${ }^{(a)}$ & $\sim 0.6$ & $\sim 1.0$ \\
\hline
\end{tabular}

${ }^{(a)}$ Calculated as the percentage of the initial natural uranium atoms that have fissioned. ${ }^{8}$ 


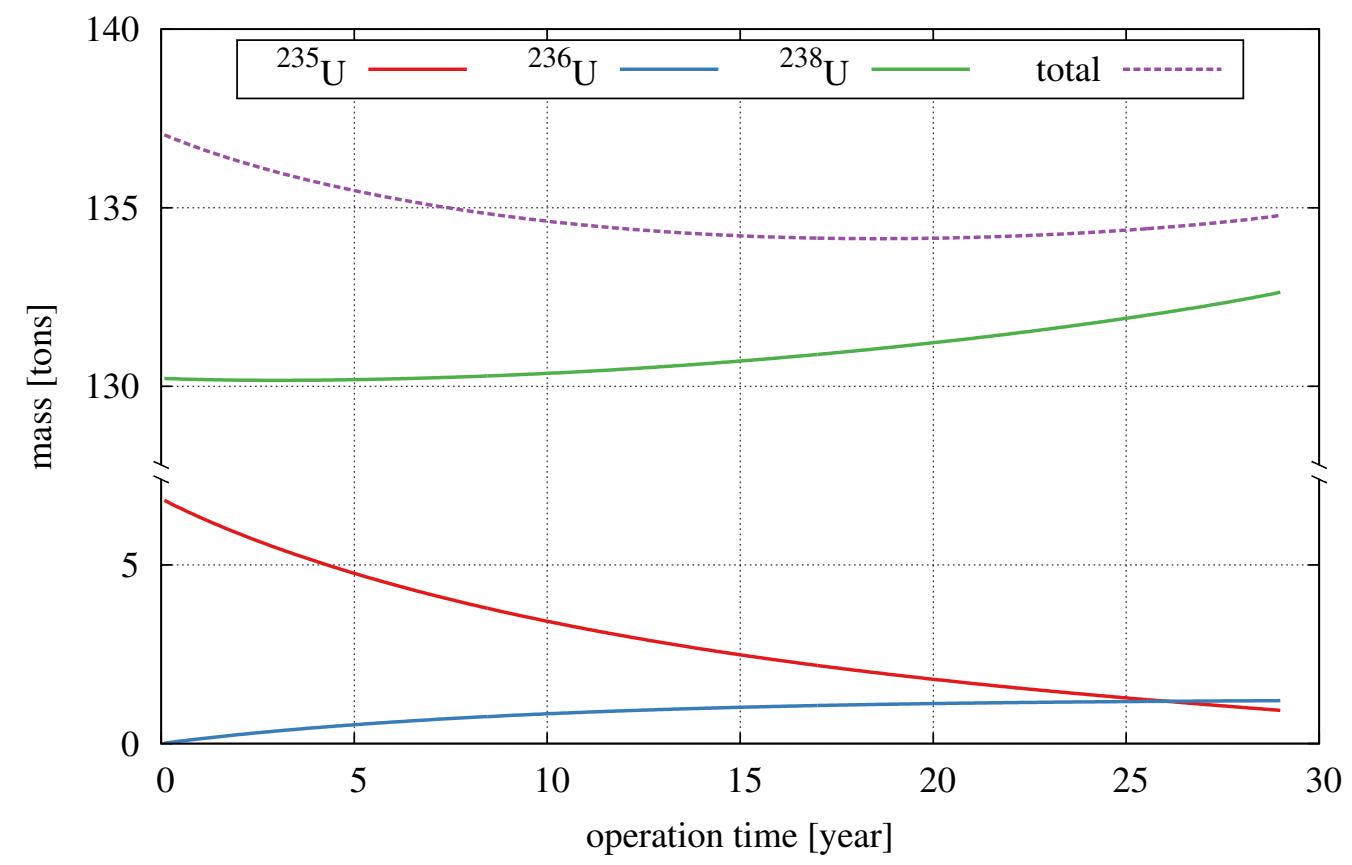

Fig. 7. ChemTriton-calculated uranium isotopic salt content during operation using the critical search function.

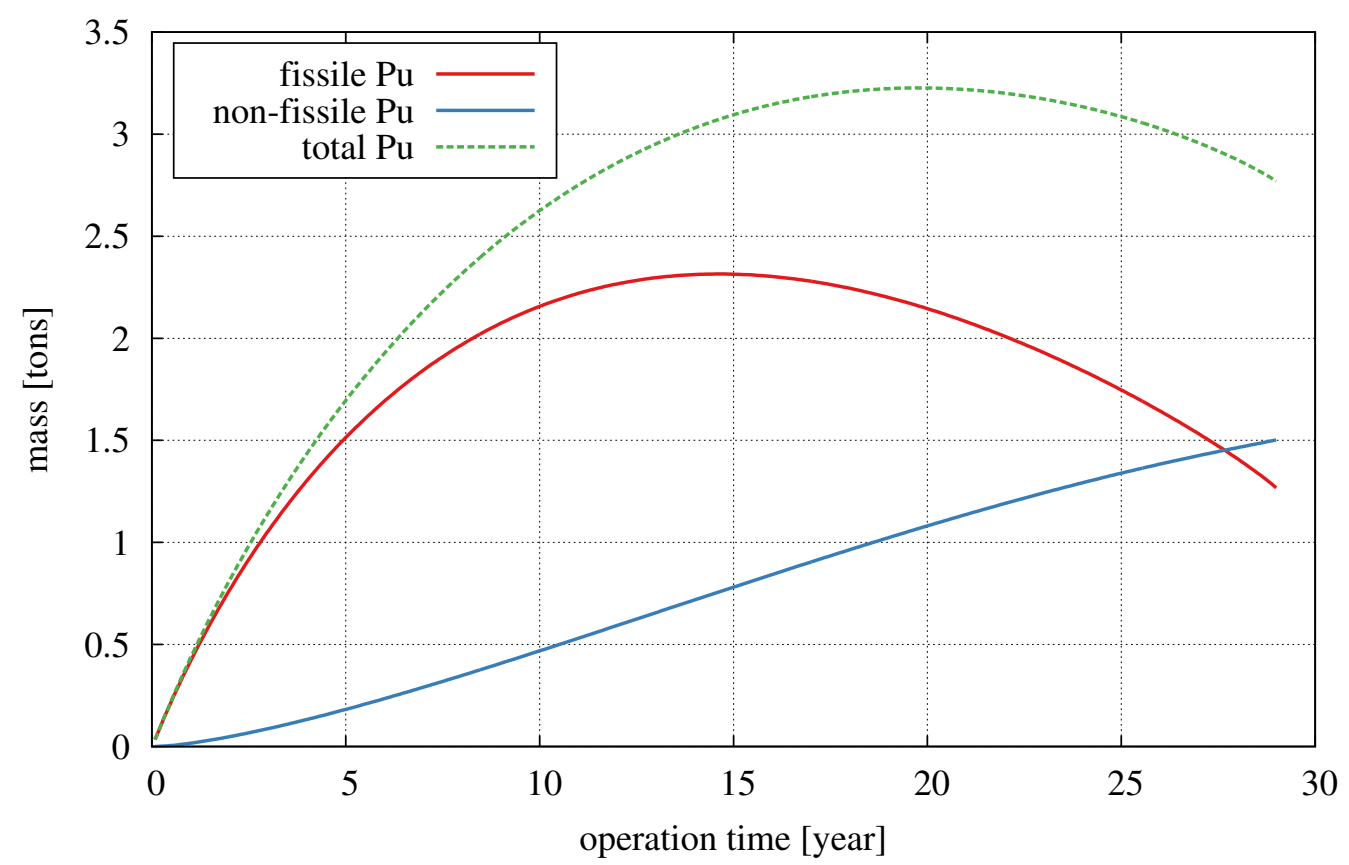

Fig. 8. ChemTriton-calculated fissile and non-fissile plutonium salt content during operation using the critical search function. 


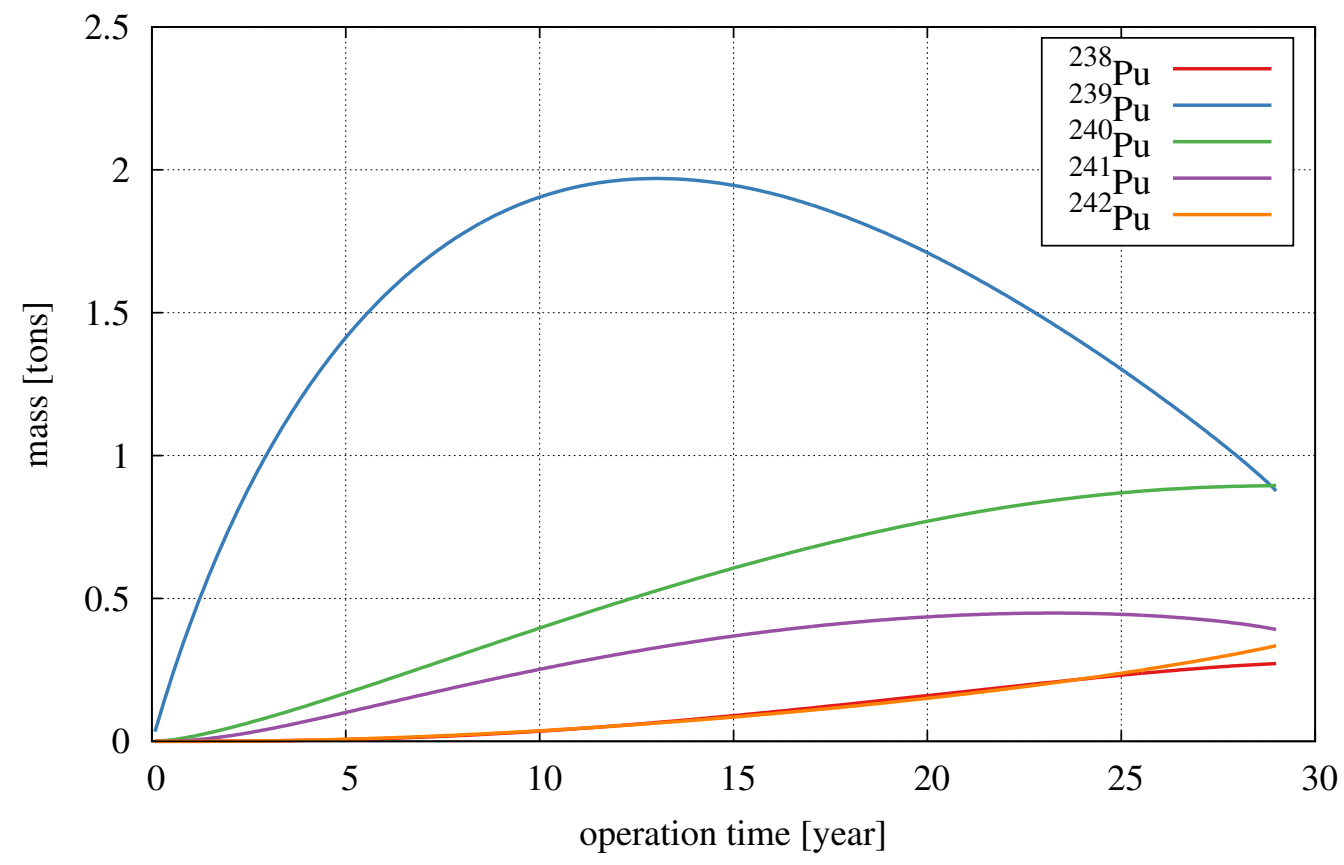

Fig. 9. ChemTriton-calculated plutonium isotopic salt content during operation using the critical search function.

reactor. But considering the use of waste material (i.e., LWR SNF) in this fueling scenario, the TAP reactor has the potential to have a better waste reduction metrics.

The TAP design using higher-enrichment fuels (e.g., 10\% LEU at startup with a 19.9\% LEU feed) will be able to operate for a longer period of time because of the high enrichment of the fuel material. This will lead to an additional reduction in long-lived actinide wastes; an $83 \%$ reduction in total actinide waste is plausible. But the use of 10-20\% LEU could be a regulatory challenge ${ }^{20}$ and would result in lower fuel utilization metrics (i.e., more natural uranium would be needed to reach a higher enrichment). Thus, this configuration is not studied herein.

Monitoring the concentration of actinides dissolved in the fuel salt is essential to operation. This concentration must be regulated to control the melting temperature of the fuel salt and avoid undesirable precipitation of heavy metals in the core and fuel loop. In the TAP reactor, the total actinide concentration is relatively constant, though the uranium concentration does decrease during operation as other heavy metals build up in the salt (Fig. 10). These molar concentrations are calculated as the simple fraction using the moles of lithium and uranium or total actinides in the fuel salt.

\subsection{TIME STEP REFINEMENT}

The results shown are from a ChemTriton calculation that used time steps of 30 days in the depletion simulation. The size of the time step was chosen after performing a set of parametric studies to determine the largest time step size that preserves the accuracy of the calculation. Using a larger time step decreases the ChemTriton calculation times, providing answers more quickly for this long 30-year simulation.

The 30-day time step appropriately captures the evolution of the $k$ eigenvalue (Fig. 11) and key fissile isotopes during operation (Figs. 12 and 13). These parametric studies used the pre-determined SVF to 


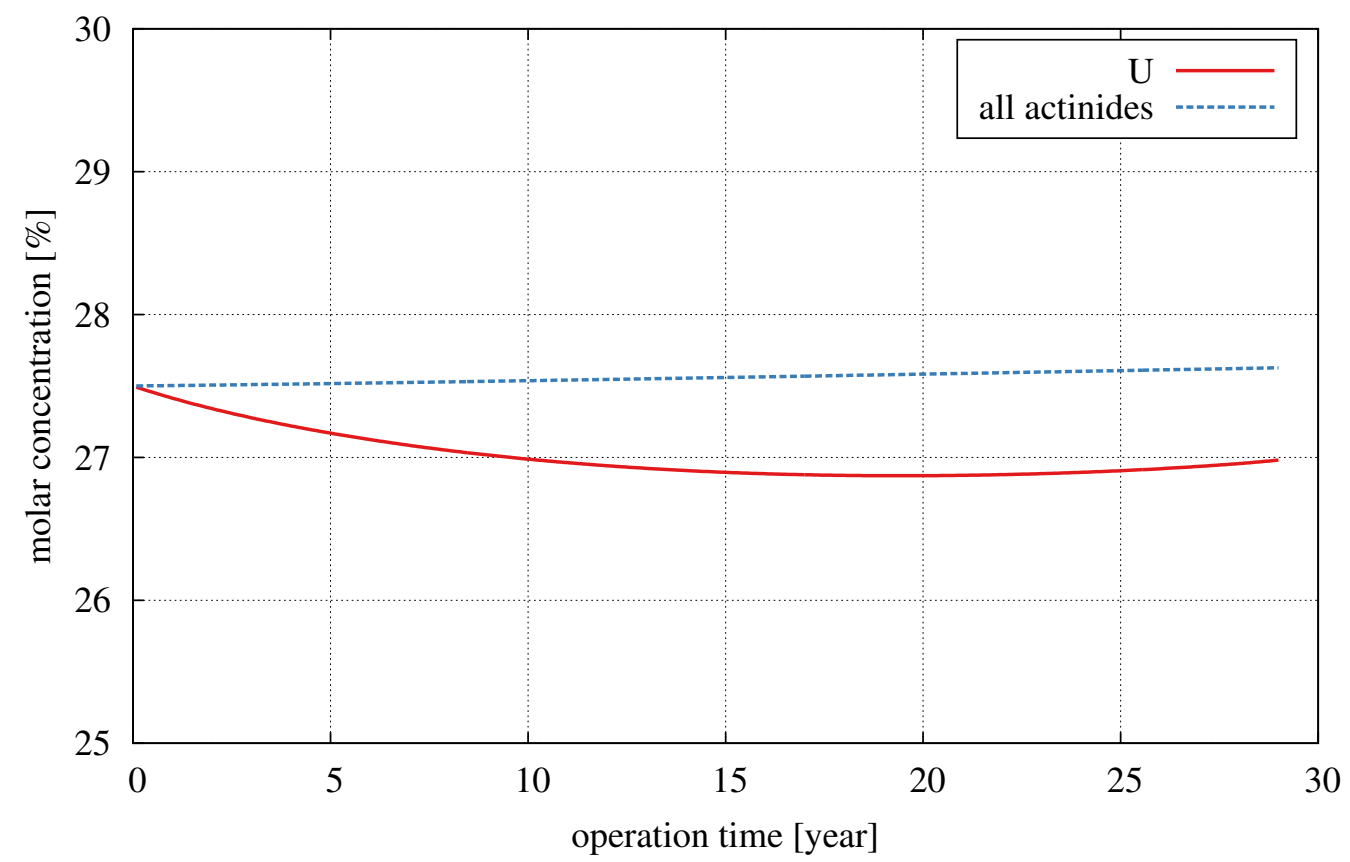

Fig. 10. ChemTriton-calculated fuel salt molar concentrations of uranium and actinides during operation using the critical search function.

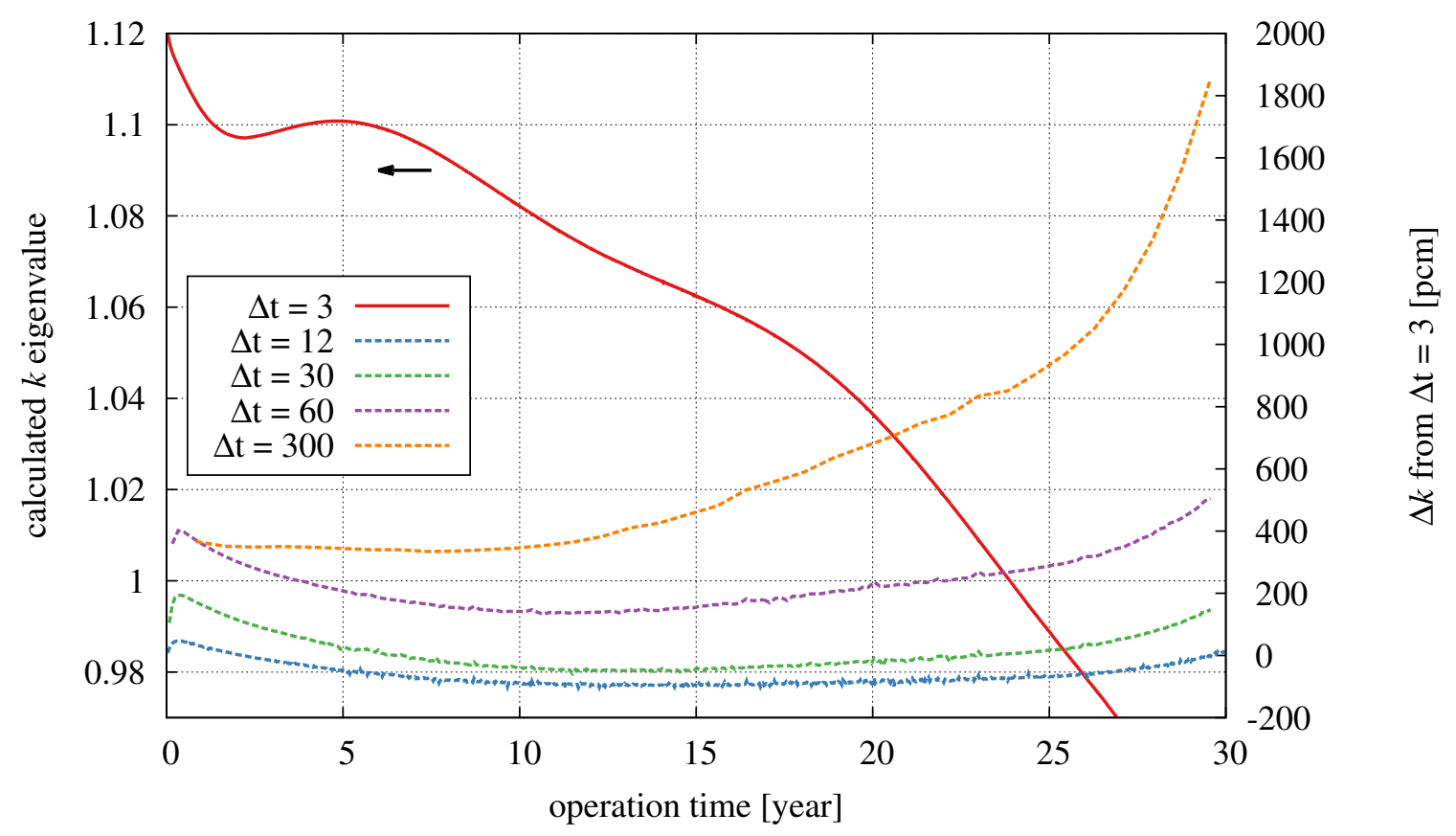

Fig. 11. ChemTriton-calculated $k$ eigenvalues during operation using the TAP-calculated pre-determined SVF and different depletion time step sizes. The SVF is adjusted with a variable pitch and a fixed moderator rod diameter of $3.6 \mathrm{~cm}$. Dashed lines denote $k$ eigenvalues plotted as differences. 


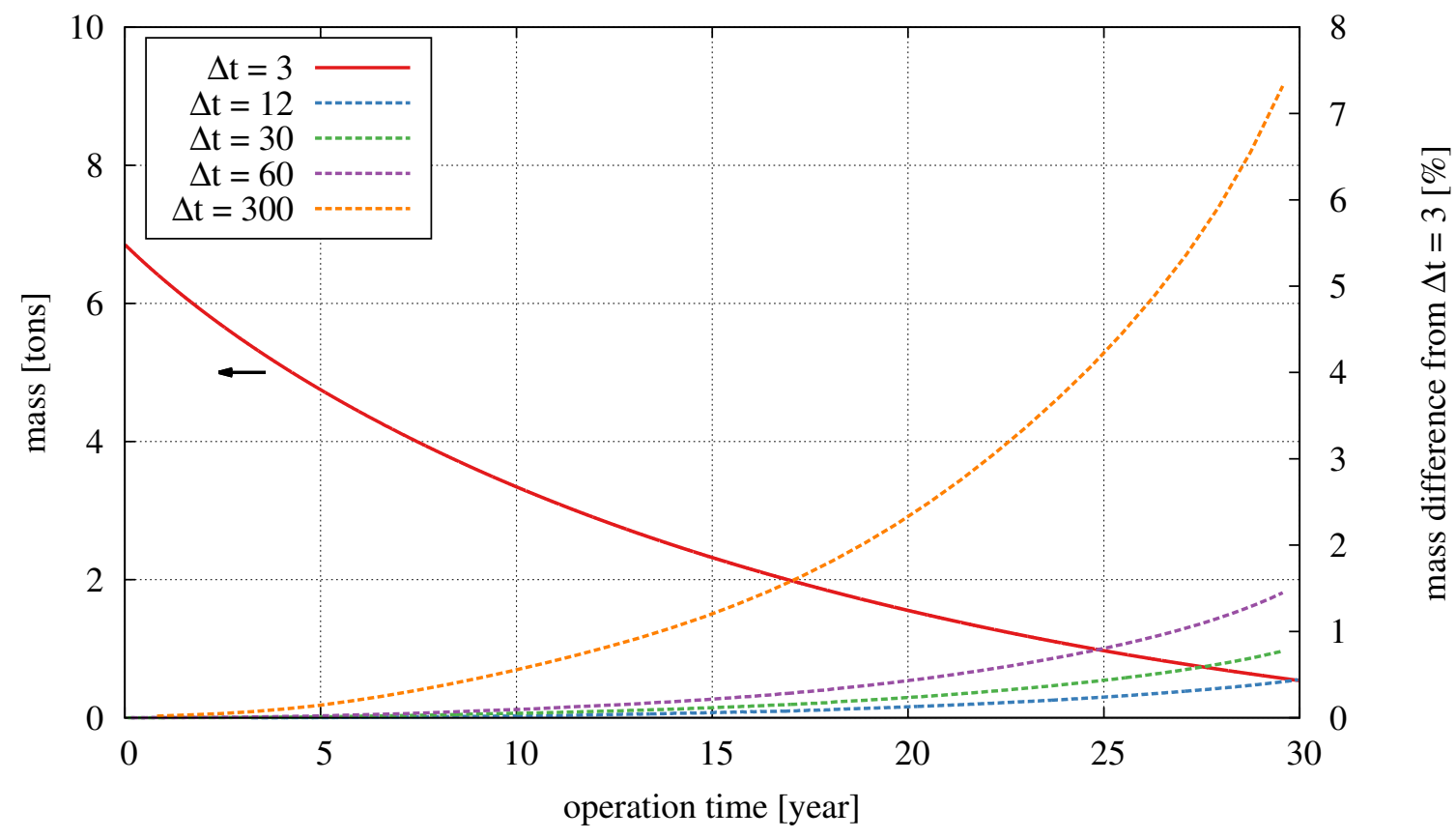

Fig. 12. ChemTriton-calculated ${ }^{235} U$ content during operation using the TAP-calculated pre-determined SVF. Dashed lines denote masses plotted as differences.

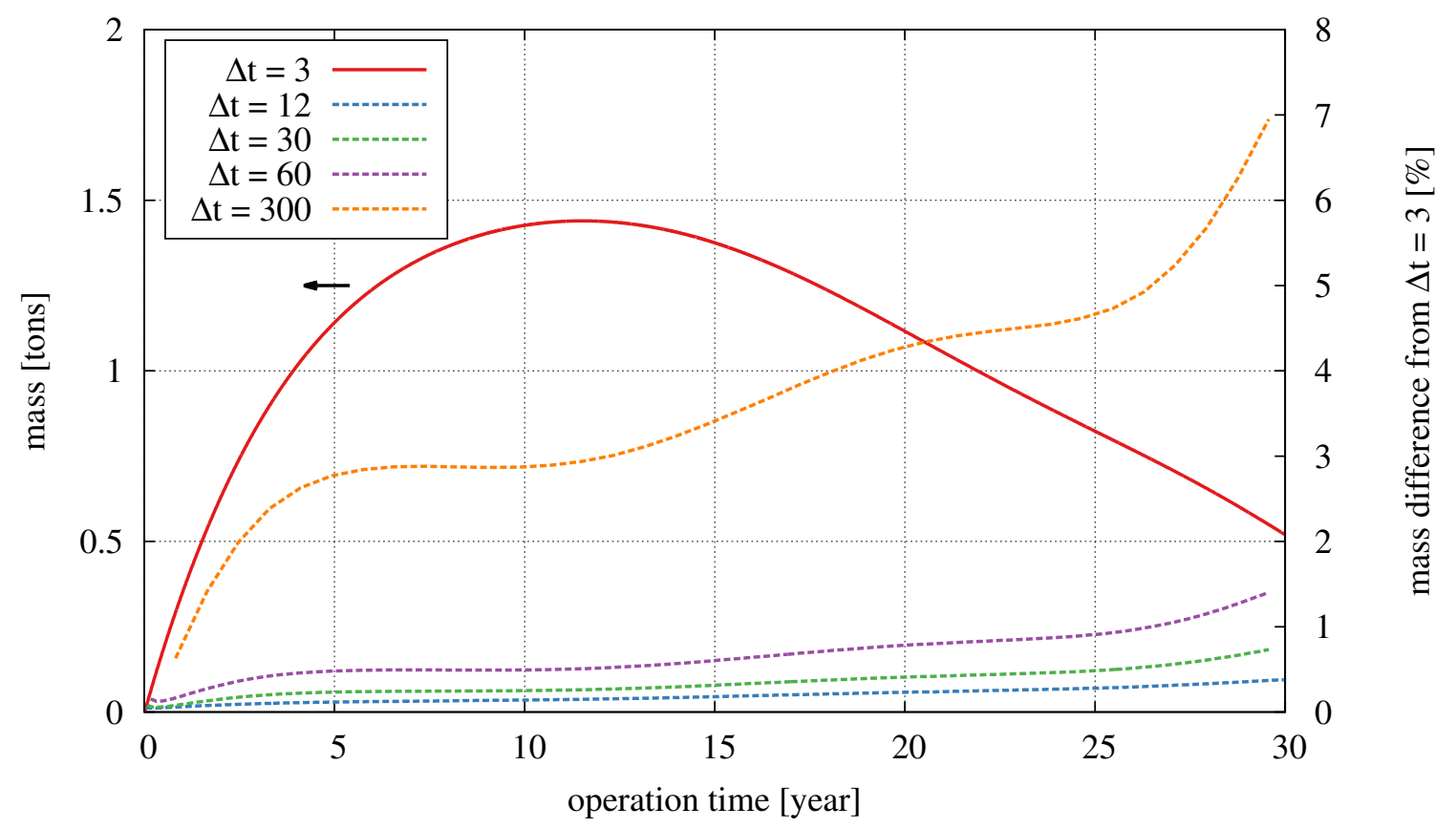

Fig. 13. ChemTriton-calculated ${ }^{239} \mathrm{Pu}$ content during operation using the TAP-calculated pre-determined SVF. Dashed lines denote masses plotted as differences. 
maintain consistency between the calculations (using the critical search would result in a different time-dependent SVF for each calculation) and were performed with the TAP-defined fission product removal rates (Table 1). Using different removal rates may change the appropriate time step size. Additionally, determining the effects of changes in the removal rates of certain elements requires smaller time steps (e.g., there is no difference between a 3-day cycle time and a 30-day cycle time when a time step of 30 days is used).

The use of a larger time step increases the predicted $k$ eigenvalue at each time step. This increase is due to the semi-continuous batch removal processes used by ChemTriton to simulate continuous removal processes. With larger time steps, more materials are removed at the beginning of each transport step, resulting in an increase in the criticality of the unit cell at the beginning of each time step. Calculations using time steps of 60 days and larger show significant differences in calculated $k$ from those using 30 days or fewer for time steps.

Using a larger time step also tends to cause an overprediction of ${ }^{239} \mathrm{Pu}$ production (Fig. 13) and a negligible underprediction of the consumption of ${ }^{235} \mathrm{U}$ (Fig. 12). With longer depletion steps, the moderator-to-fuel ratio is updated less frequently during the ChemTriton calculation. In addition, the geometry at the beginning of each time step is used in the transport calculation; this geometry has the highest SVF of any point during the time step. The spectrum calculated using this geometry will be harder than the true spectrum averaged over the time step; the difference between these two quantities only grows as the depletion step is lengthened. A harder spectrum leads to a higher breeding rate of ${ }^{239} \mathrm{Pu}$.

\subsection{FUEL FEED MASS AND ENRICHMENT}

The previous results shown are from a ChemTriton calculation that used a TAP-specified 5\% LEU feed rate of $480 \mathrm{~kg} / \mathrm{y}$ throughout the calculation. This feed rate is approximately equal to the rate of consumption of fissile material in the reactor and is intended to keep the total actinide concentration constant during operation. Additional calculations were run to determine the effects of feed material enrichment and total mass on the operation of the core. These calculations use the ChemTriton critical search function instead of the pre-determined SVF.

Higher feed material enrichments result in longer core lifetimes (Fig. 14) because they enable operation with a higher SVF for a longer period of time (Fig. 15). The time-dependent criticality conditions are different for each case because the core leakage is dependent on SVF instead of time. The difference between the ChemTriton-calculated SVF of each case is apparent early on in the calculation; the rate of moderator rod insertion is immediately higher in cases with lower-enrichment feeds. This is to overcome the lower replacement rate of fissile ${ }^{235} \mathrm{U}$, the addition of the growing amount of non-fissile ${ }^{238} \mathrm{U}$, and the lower effective conversion ratio in cases with decreasing enrichment. Operating with a higher SVF increases the total plutonium production in the core (Fig. 16) owing to hardening of the spectrum. This increase in operating lifetime supports the expected increase in burnup for a TAP reactor fueled with a higher-enrichment LEU fuel.

Adjusting the feed material rates also impacts the lifetime of the core (Fig. 17). In these cases, ChemTriton is run for various relative amounts (0-200\%) of the $480 \mathrm{~kg} / \mathrm{y}$ TAP-specified feed rate. Increasing this feed rate adds more fissile and fertile material to the fuel salt, allowing the reactor to operate for a longer period of time. But the impact of this change is not apparent until longer operating times with respect to the enrichment cases. This is also seen in the calculated SVF, which varies relatively little between the different cases over the first several years of operation (Fig. 18). As in the enrichment cases, the addition of more feed material increases the breeding of fissile ${ }^{239} \mathrm{Pu}$ (Fig. 19) but the amount of fissile plutonium at core EOL increases with the feed rate, suggesting that the additional ${ }^{238} \mathrm{U}$ loaded into the core 


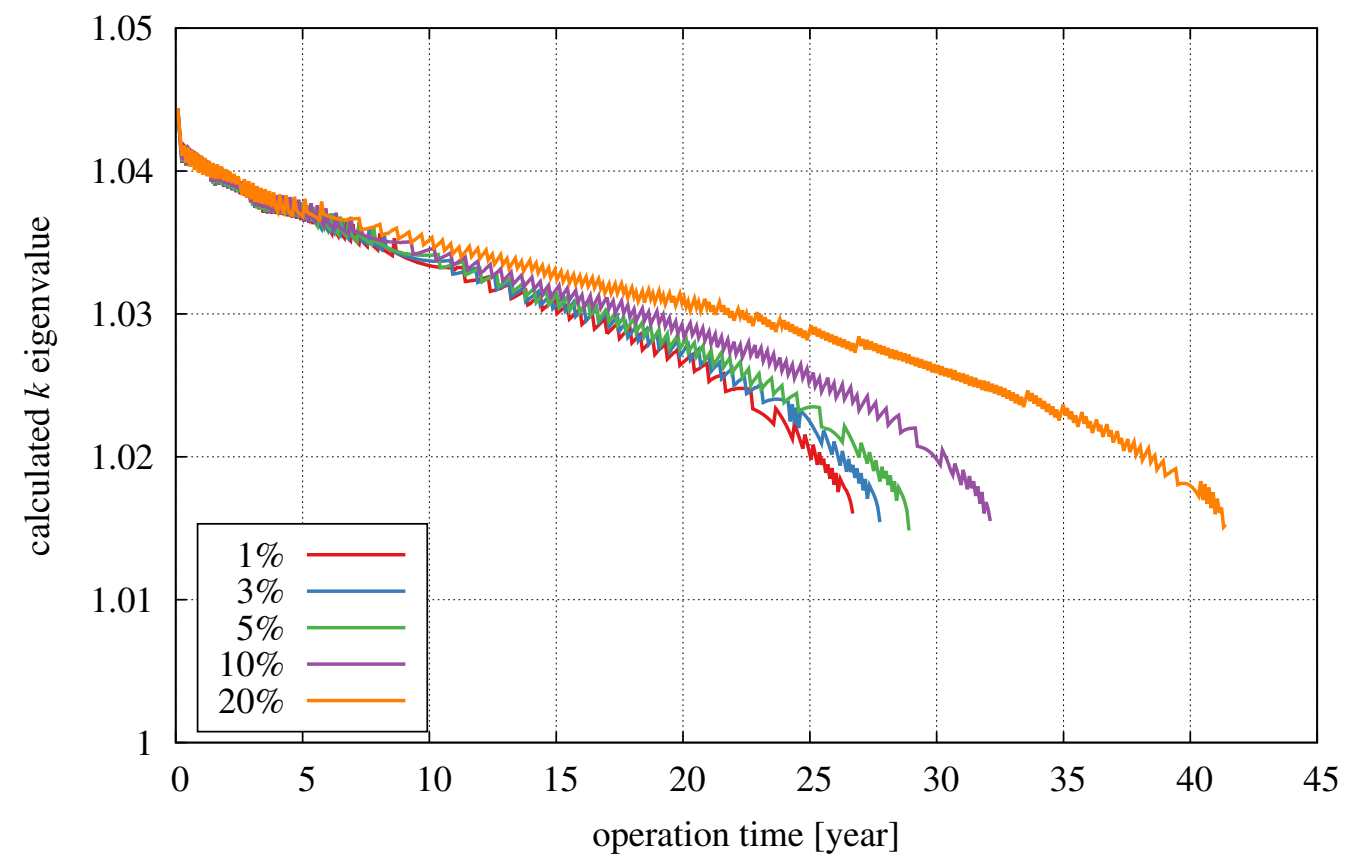

Fig. 14. ChemTriton-calculated $k$ eigenvalues during operation using the critical search function for various enrichments of the feed material.

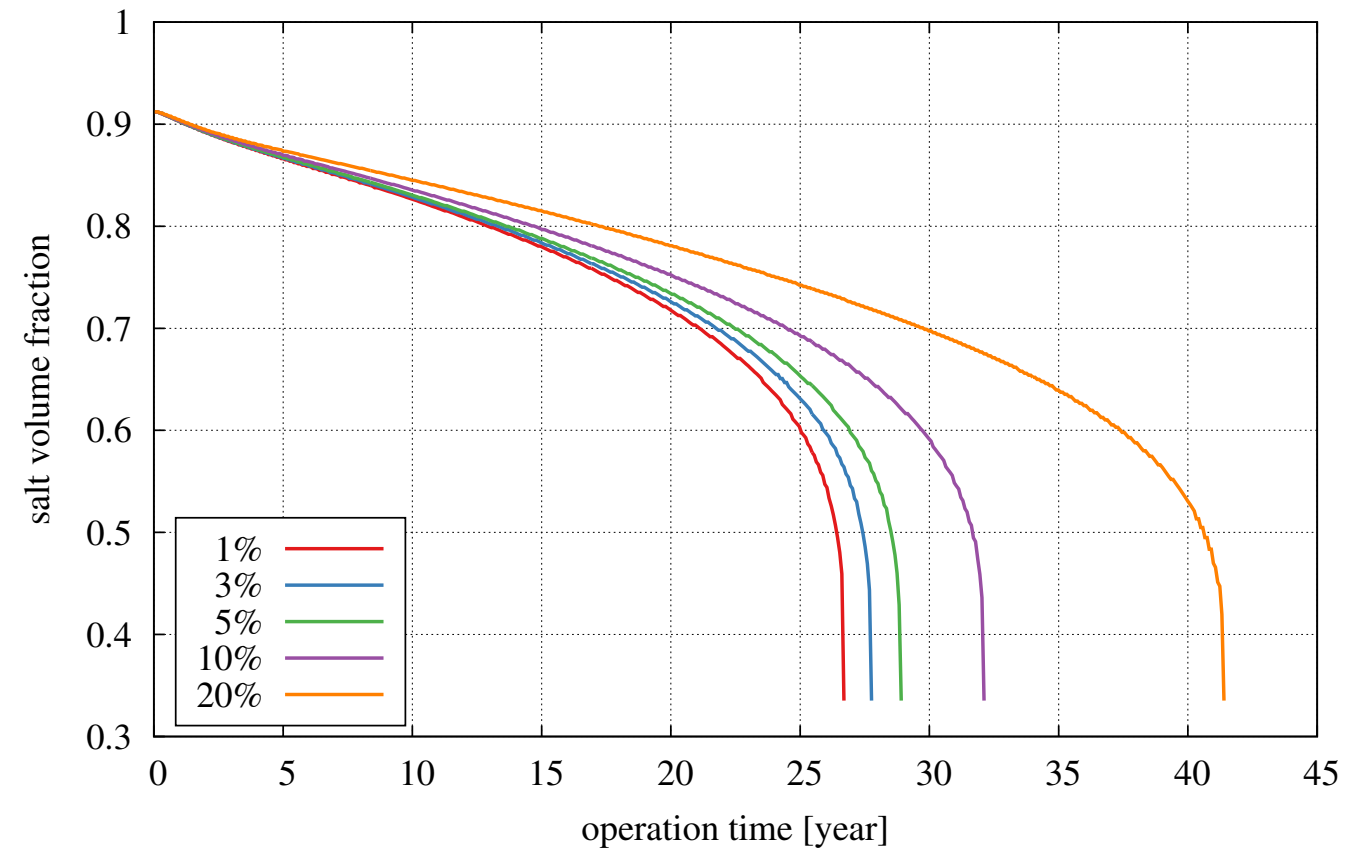

Fig. 15. ChemTriton-calculated SVF during operation using the critical search functions for various enrichments of the feed material. 


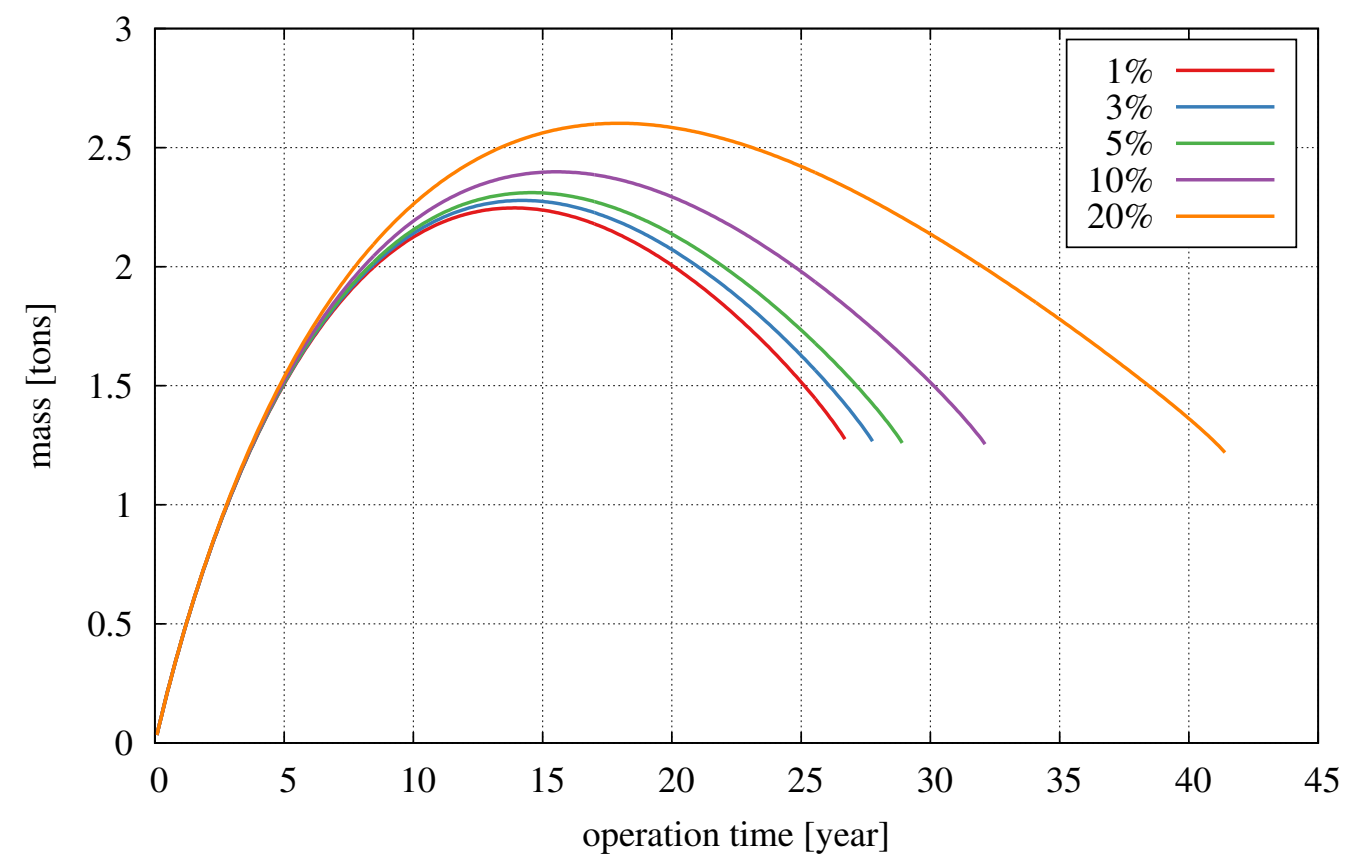

Fig. 16. ChemTriton-calculated fissile plutonium mass during operation for various enrichments of the feed material.

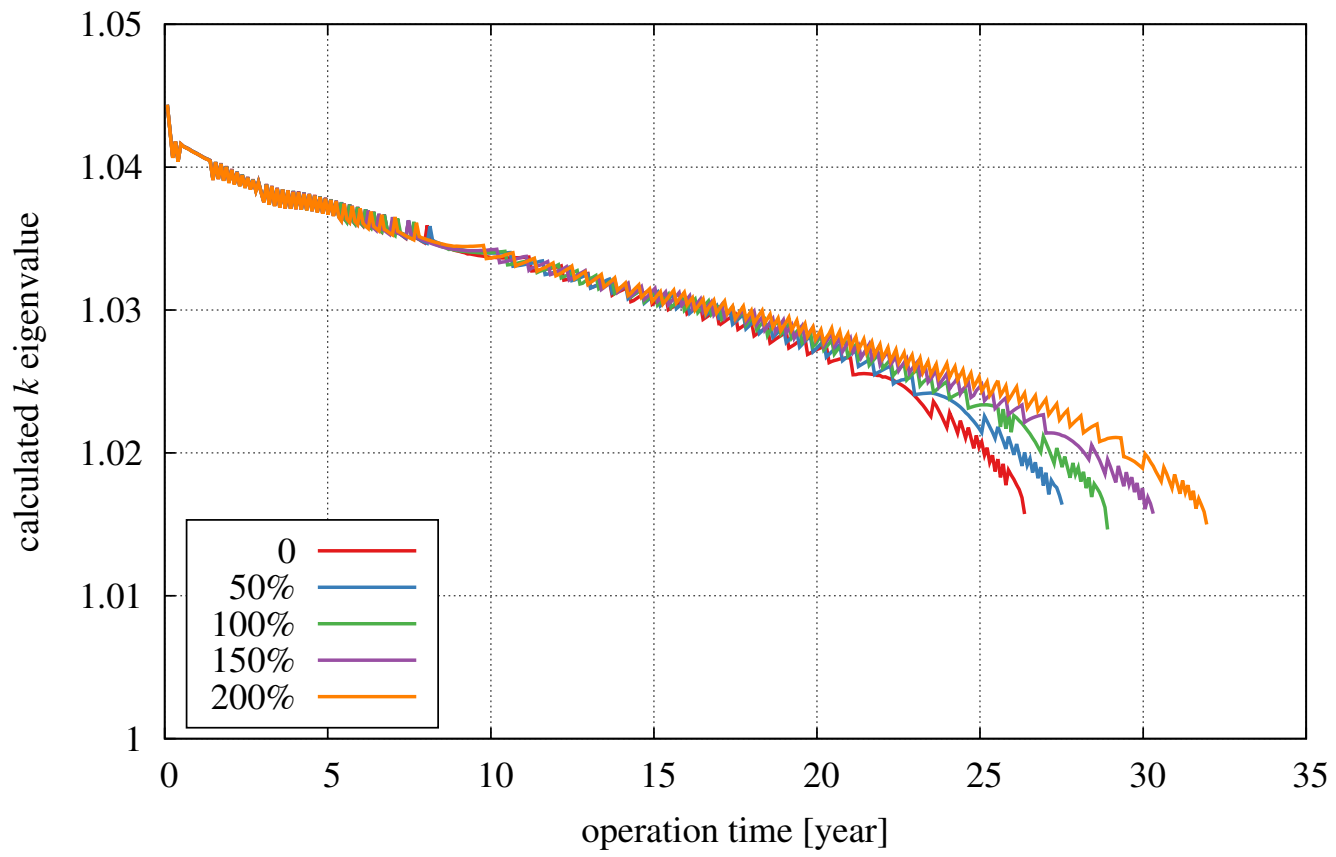

Fig. 17. ChemTriton-calculated $k$ eigenvalues during operation for various feed material rates. 


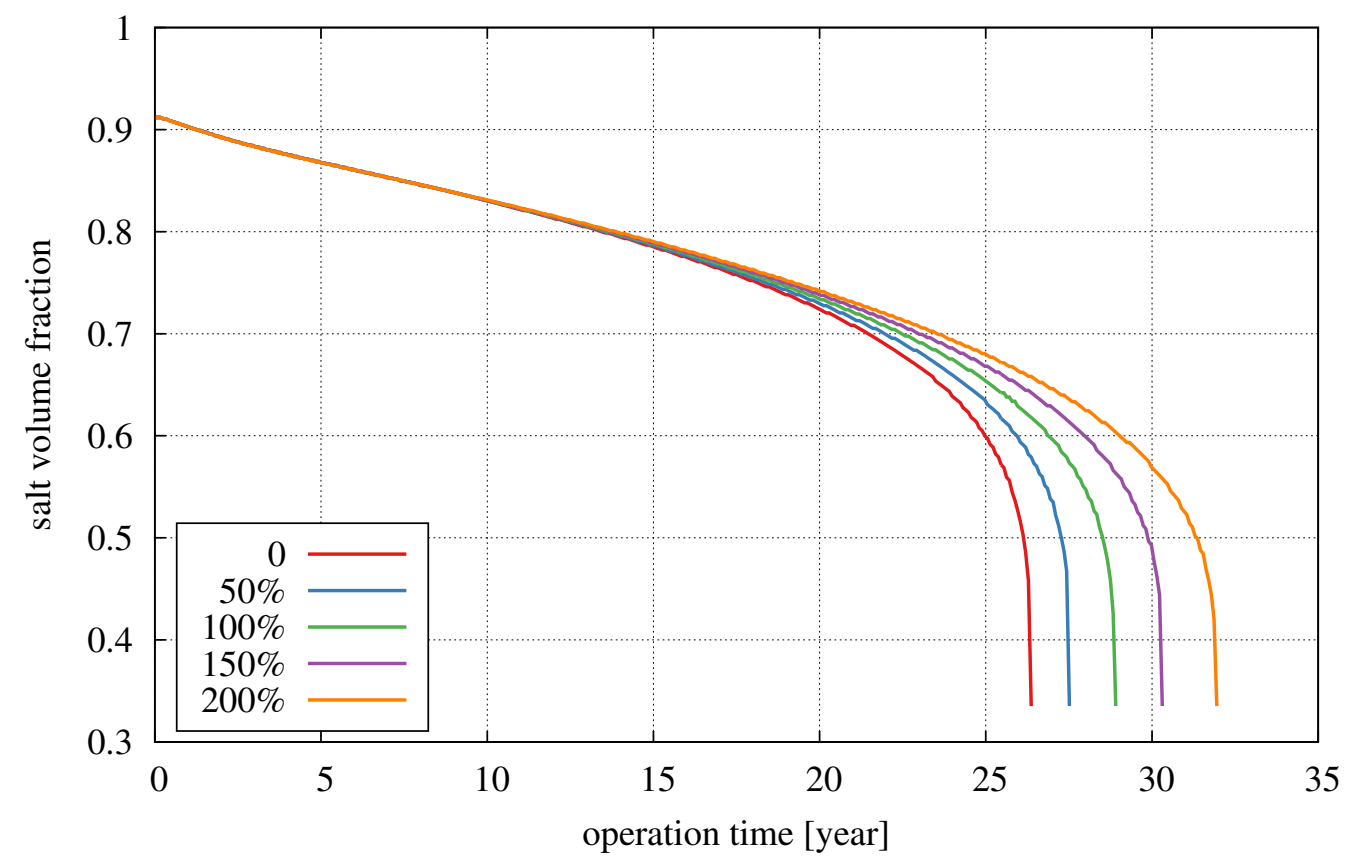

Fig. 18. ChemTriton-calculated SVF during operation using the critical search functions for various feed material rates.

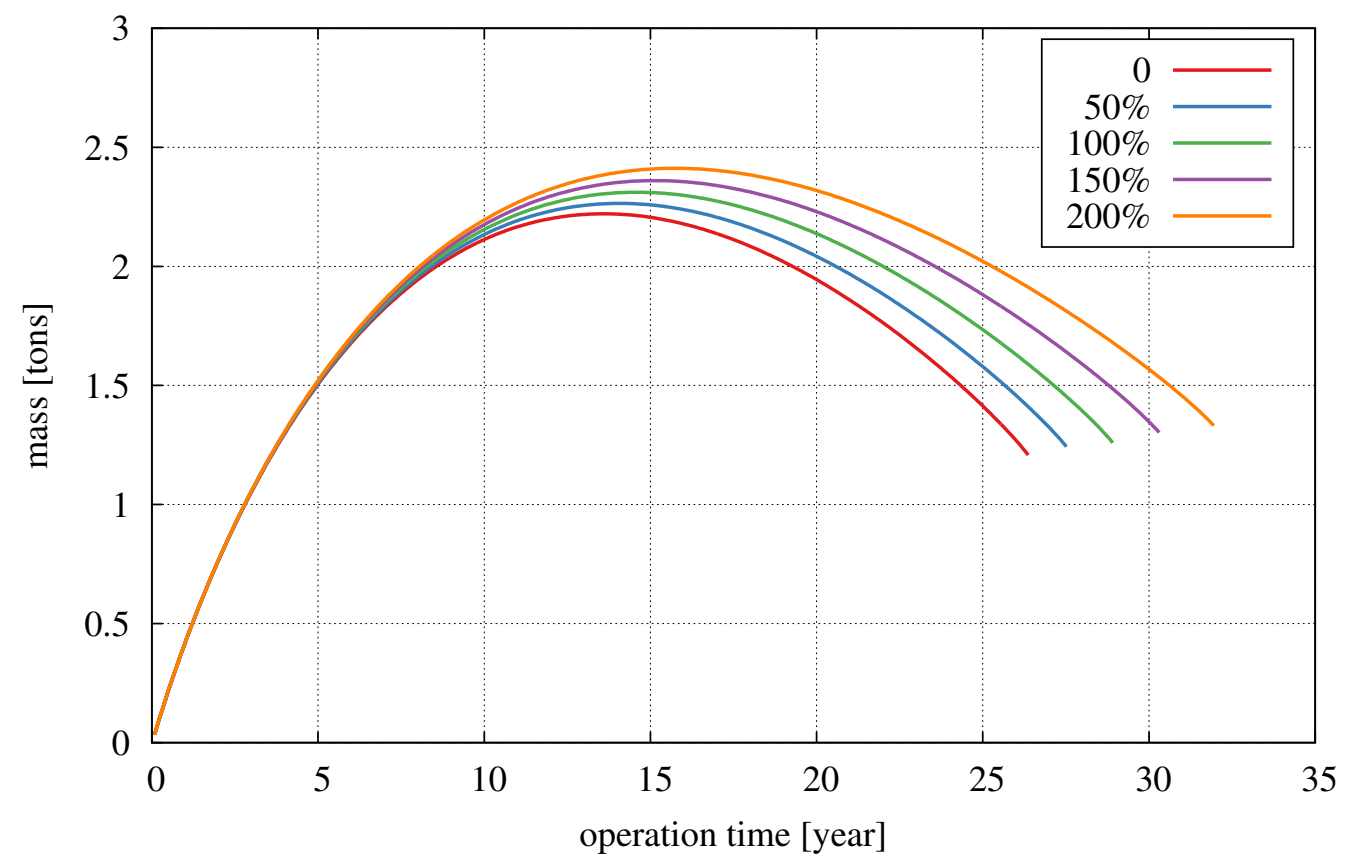

Fig. 19. ChemTriton-calculated fissile plutonium mass during operation for various feed material rates. 
has an impact at EOL. For the enrichment cases, the discharge fissile plutonium mass is unaffected by the feed enrichment.

Adjusting the feed material rates also changes the total uranium (Fig. 20) and actinide (Fig. 21) concentrations in the fuel salt. The changes in actinide and uranium molar concentrations affect physical properties of the fuel salt and must be quantified to avoid operational issues. The $480 \mathrm{~kg} / \mathrm{y}$ feed rate properly maintains the total actinide concentration in the fuel salt, but a higher feed rate is possible if maintaining the uranium concentration is the primary objective.

A comparison of the effects of the enrichment and masses on the reactor operational lifetime shows some overlap at lower feed rates and enrichments (Fig. 22). This shows that loading no feed material is as detrimental to operational lifetime as loading poorly enriched material $(<1 \%)$. In this case, loading no feed material is likely preferential, assuming there are no strict constraints on uranium concentration to maintain the physical properties of the salt. Correcting for the total mass of material loaded into the core (this is different for the mass cases), the operational lifetime is converted to discharge burnup (Fig. 23). This shows that, despite increasing core lifetime, changing the total feed rate of material during operation has no effect on the discharge burnup and thus offers little benefit with regard to fuel cycle performance. Increasing the enrichment of the feed material greatly impacts the discharge burnup at a rate of 2.0 GWd/MTU per percentage point of enrichment. This supports the higher burnup metrics ${ }^{4}$ of a TAP design using a higher-enrichment fuel.

\subsection{ISOTOPIC REMOVALS}

The previous results shown are from a ChemTriton calculation that simulated the online removal of the list of TAP-specified elements with cycle times from previous work. ${ }^{16}$ To determine the effective worth of these elements and their effects on the lifetime of the core, ChemTriton calculations were repeated with

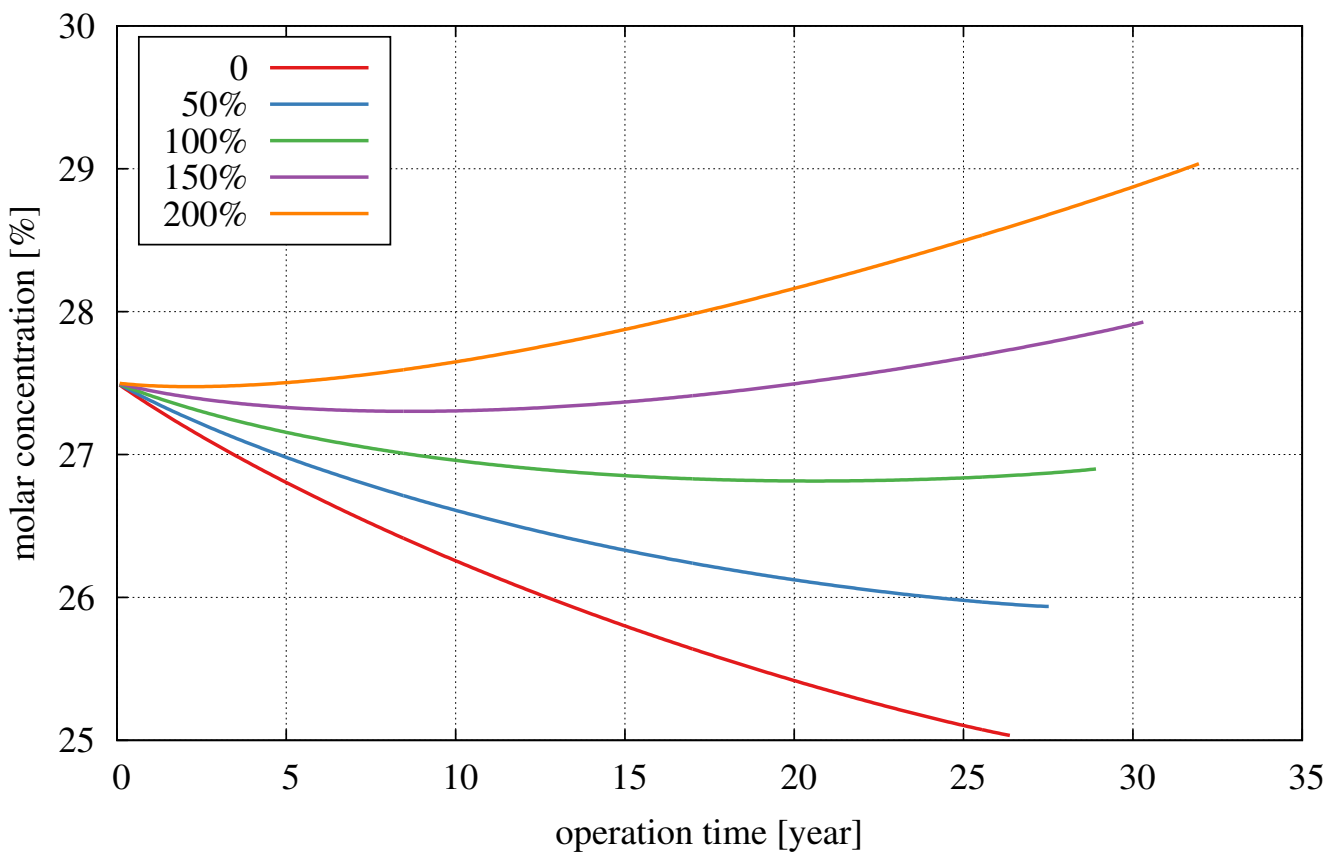

Fig. 20. ChemTriton-calculated fuel salt molar concentrations of uranium for various feed material rates. 


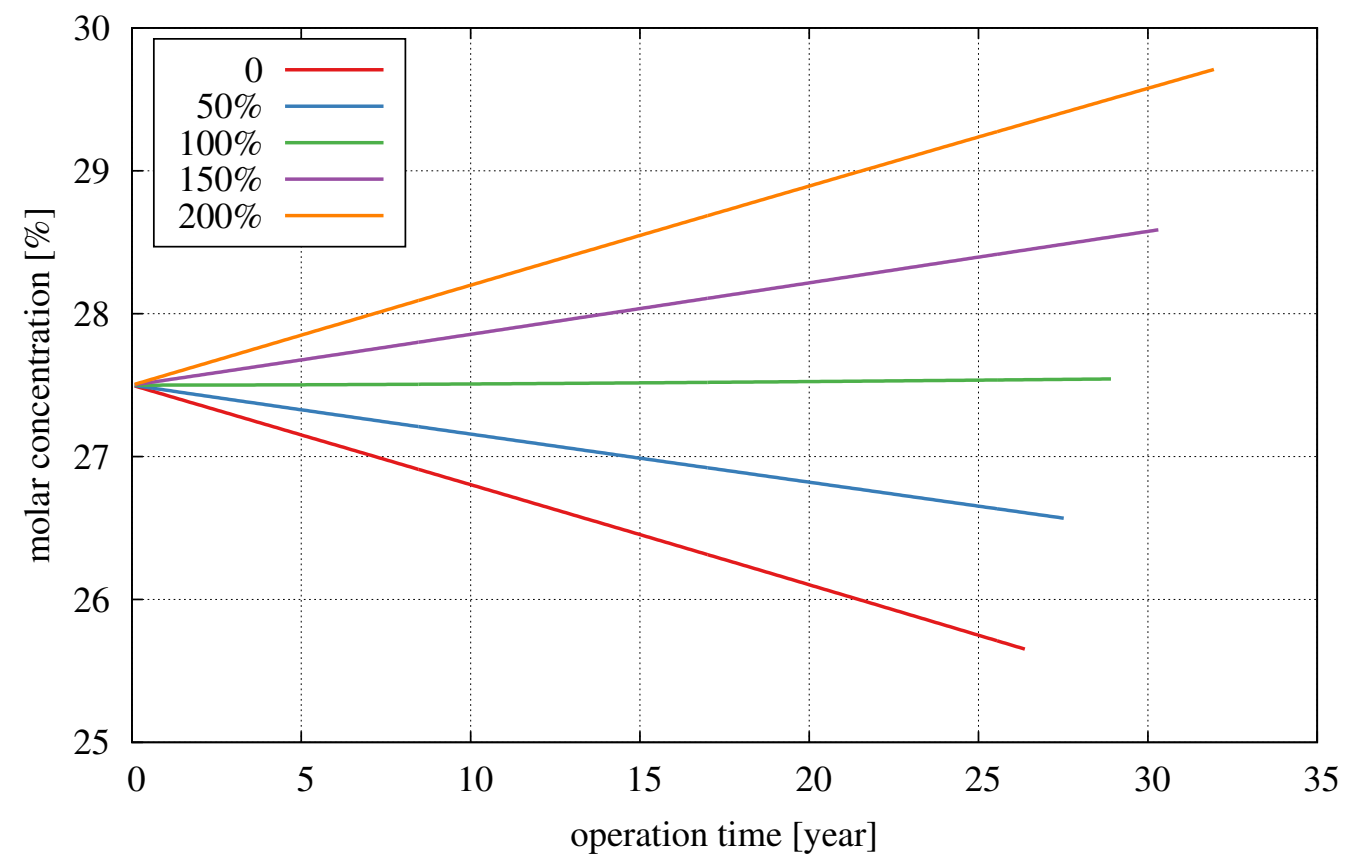

Fig. 21. ChemTriton-calculated fuel salt molar concentrations of actinides for various feed material rates.

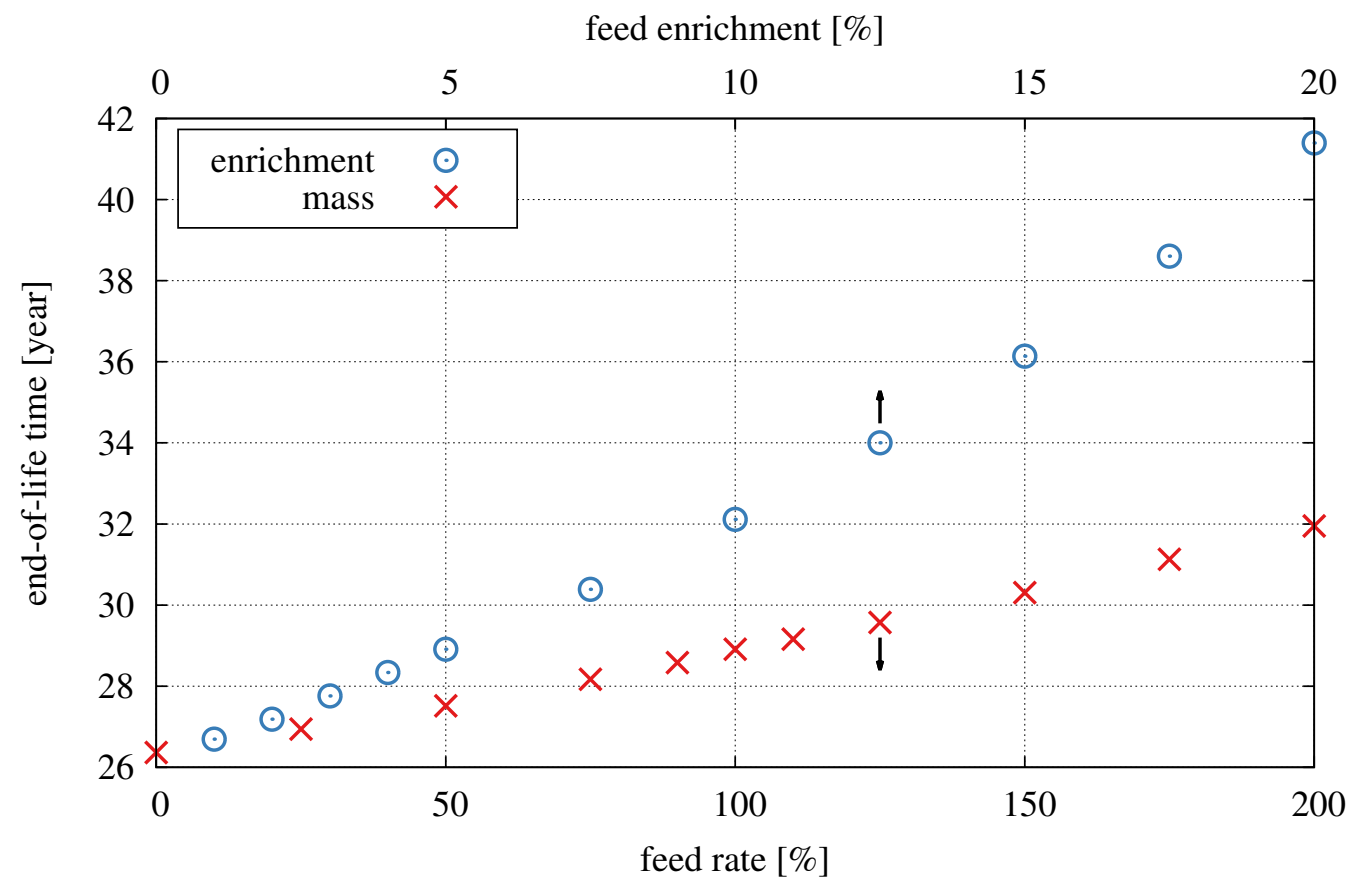

Fig. 22. ChemTriton-calculated core EOL for various enrichments and rates of feed materials. 


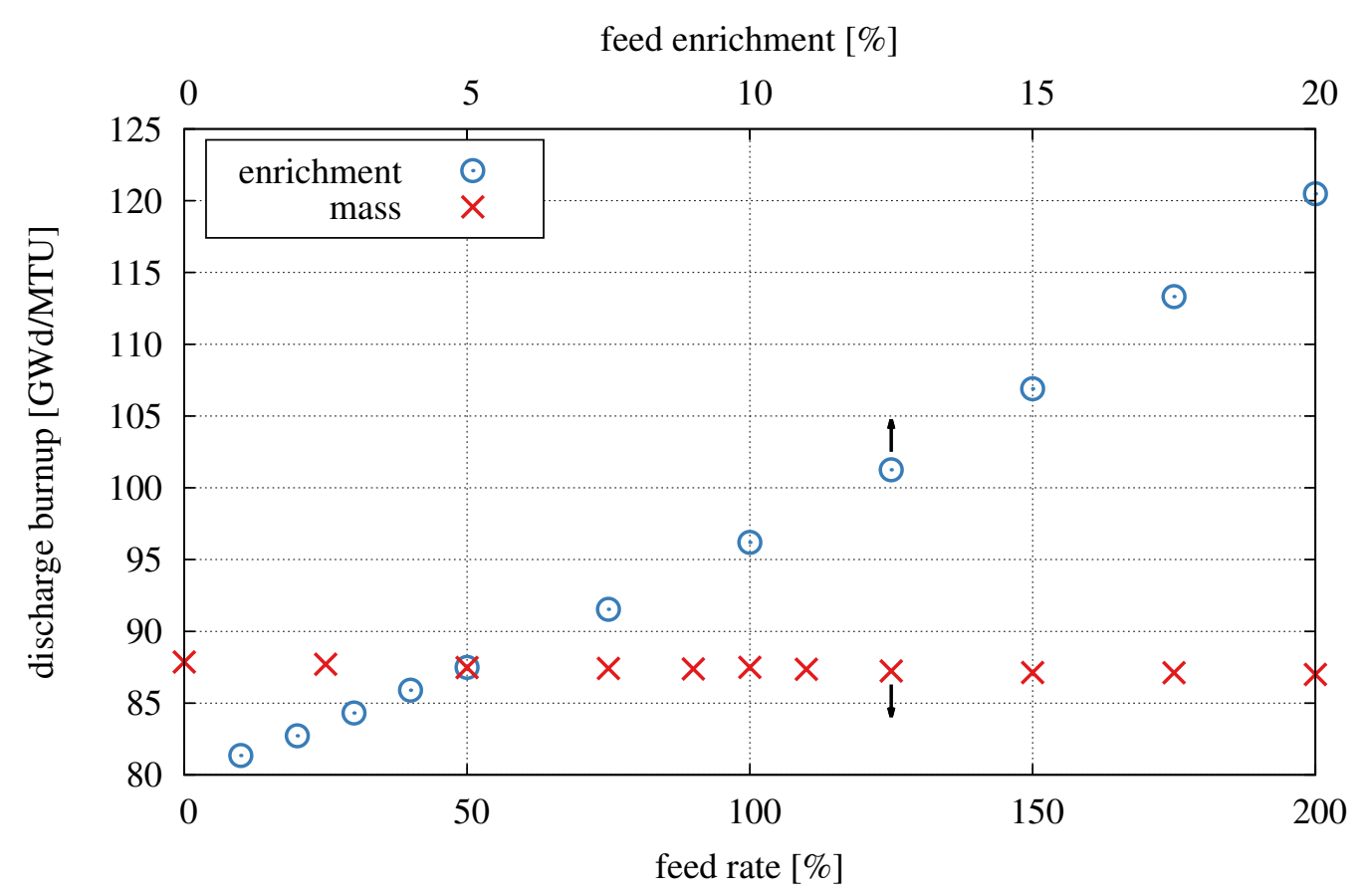

Fig. 23. ChemTriton-calculated discharge burnup for various enrichments and rates of feed materials.

different cycle times for each of the processing groups (Table 1). Cycle times were varied from 30-1000 days. Volatile gases and noble metals were omitted from this parametric study because these are considered salt treatment groups (i.e., it is expected that these materials must be removed with high efficiency to avoid operational issues in the core). The removal of these two processing groups has been shown to have a significant effect on reactivity during operation. ${ }^{9}$

Removal of the seminoble metals, volatile fluorides, and discard processing groups offers no neutronic or fuel cycle benefits to the design. That is because these materials are neutronically negligible because of either low fission yield or small cross sections. Removal of these materials may have other material-related benefits (e.g., reducing corrosion).

Removal of the rare earth elements has a larger impact on the overall reactor lifetime (Fig. 24), as has been shown for thermal MSRs. ${ }^{9}$ These elements have high absorption cross sections, so a higher rate of removal returns a longer core lifetime. Neutronically, it is desirable to develop efficient removal processes for these rare earth elements. The difference between removal and no removal of these isotopes is 3 years of operation and an additional $8.0 \mathrm{GWd} / \mathrm{MTU}$ in discharge burnup (Fig. 25). 


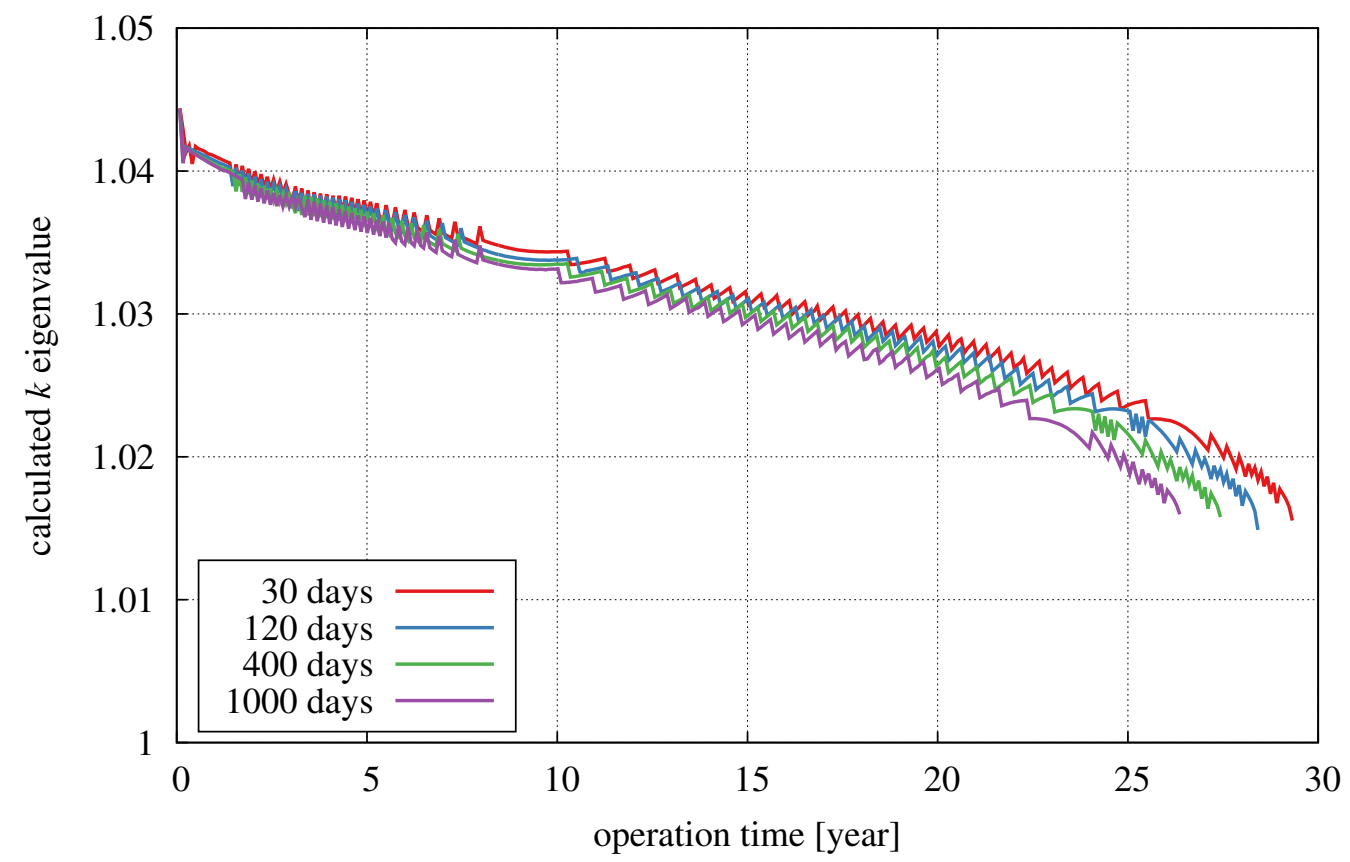

Fig. 24. Comparison of ChemTriton-calculated $k$ eigenvalues during operation using the critical search function for various cycle times for rare earth elements.

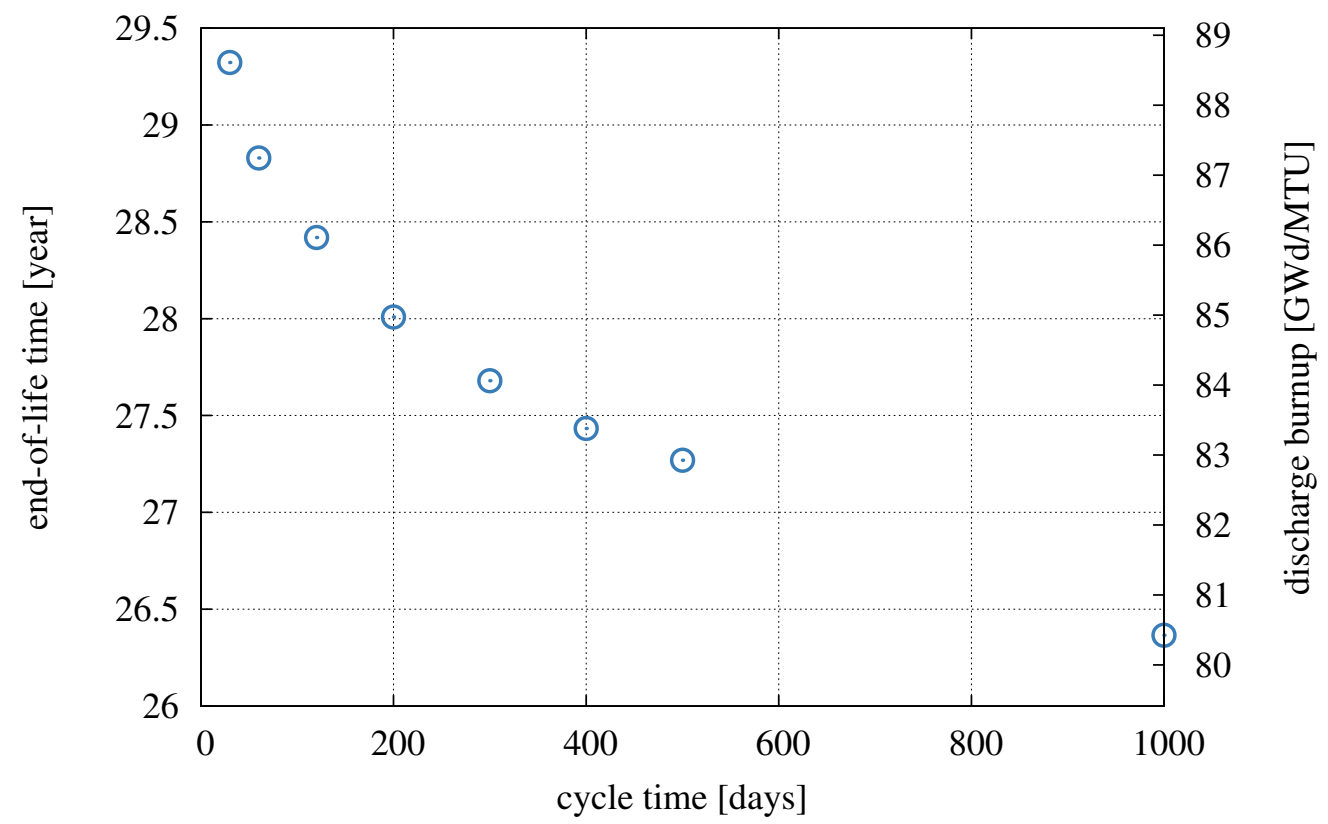

Fig. 25. ChemTriton-calculated core EOL and discharge burnup for various cycle times for rare earth elements. 



\section{SUMMARY AND CONCLUSIONS}

Analysis of the TAP MSR design is under way as part of the GAIN initiative, and the first phase of the analysis using 2D models is complete. The TAP MSR design achieves high burnup using movable moderator rods to shift the neutron spectrum from mostly epithermal at BOL to thermal at EOL. Preliminary 2D analysis with ChemTriton shows that the hardened spectrum over the first 15 years of operation breeds sufficient fissile plutonium to drive the fuel to a burnup of $87.8 \mathrm{GWd} / \mathrm{MTU}$ after 29.0 years of operation. Along with the ChemTriton-calculated SVF, these metrics agree with TAP-specified parameters ${ }^{3,4}$ and show the design to be a viable means of reducing annual actinide waste production.

Additional calculations were performed to explore the design space to quantify the effect of potential design changes on the reactor operation and fuel cycle performance. These included feed material studies to determine the effects of feed rates and enrichment, isotopic removal studies to determine the worth of improving the removal efficiency of different processing groups, and ChemTriton time step studies to help increase the efficiency of calculations. This research informs TAP of the effects of these design changes and provides the groundwork for more high-fidelity simulations in which calculation times may be a bottleneck.

Current efforts are focused on the development of a quarter-core 3D model of the TAP reactor and the tools necessary to analyze this model. Several effects will be explored with the 3D models, including reactivity coefficients, spatial power shapes (radial and axial), partial moderator rod insertion, axial and radial reflector design, core structure design, and fluence to moderator rods. These simulations will demand more computational time but are essential for modeling the heterogeneities of the TAP core design. 



\section{REFERENCES}

1. S. Brinton, "The Advanced Nuclear Industry," Third Way, June 15, 2015.

http://www.thirdway.org/report/the-advanced-nuclear-industry. Accessed March 1, 2016.

2. US Department of Energy, "Gateway for Accelerated Innovation in Nuclear," November 2015. http://energy.gov/technologytransitions/gateway-accelerated-innovation-nuclear. Accessed August 8, 2016.

3. Transatomic Power Corporation, Transatomic Technical White Paper, V 2.0, July 2016. http://www.transatomicpower.com. Accessed July 2016.

4. Transatomic Power Corporation, Transatomic Neutronics Overview, V 1.0, July 2016. http://www.transatomicpower.com. Accessed July 2016.

5. P. N. Haubenreich and J. R. Engel, "Experience with the Molten-Salt Reactor Experiment," Nuclear Applications and Technology 8, 118-136 (1970).

6. Transatomic Power Corporation, Transatomic Power Technical White Paper, V 1.0.1, March 2014. http://www.transatomicpower.com. Accessed May 2014.

7. M. Massie and L. C. Dewan, "Nuclear Reactors and Related Methods and Apparatus," US Patent US 20130083878 A1, filed October 3, 2011.

8. R. Wigeland et al., Nuclear Cycle Evaluation and Screening-Final Report: Appendix B, INL/EXT-14-31465 (2014).

9. B. R. Betzler, J. J. Powers, and A. Worrall, "Molten Salt Reactor Neutronics and Fuel Cycle Modeling and Simulation with SCALE," Annals of Nuclear Energy, in press.

10. S. M. Bowman, "SCALE 6: Comprehensive Nuclear Safety Analysis Code System," Nuclear Technology 174 (2011).

11. M. D. DeHart and S. M. Bowman, "Reactor Physics Methods and Analysis Capabilities in SCALE," Nuclear Technology 174(2), 196-213 (2011).

12. J. J. Powers, T. J. Harrison, and J. C. Gehin, "A New Approach for Modeling and Analysis of Molten Salt Reactors Using SCALE," Proc. Int. Conf. Mathematics and Computational Methods Applied to Nuclear Science and Engineering (M\&C 2013), Sun Valley, Idaho (2013).

13. B. R. Betzler, J. J. Powers, and A. Worrall, "Modeling and Simulation of the Start-up of a Thorium-Based Molten Salt Reactor," Proc. Int. Conf. PHYSOR 2016, Sun Valley, Idaho (2016).

14. N. R. Brown, J. J. Powers, B. Feng, F. Heidet, N. E. Stauff, G. Zhang, M. Todosow et al., "Sustainable Thorium Nuclear Fuel Cycles: A Comparison of Intermediate and Fast Neutron Spectrum Systems," Nuclear Engineering and Design 289, 252-265 (2015).

15. J. J. Powers, J. C. Gehin, A. Worrall, T. J. Harrison, and E. E. Sunny, "An Inventory Analysis of Thermal-Spectrum Thorium-Fueled Molten Salt Reactor Concepts," Proc. Int. Conf. PHYSOR 2014, Kyoto, Japan (2014).

16. J. C. Gehin and J. J. Powers, "Liquid Fuel Molten Salt Reactors for Thorium Utilization," Nuclear Technology, 194(2), (2016).

17. C. Nicolino, G. Lapenta, S. Dulla, and P. Ravetto, "Coupled Dynamics in the Physics of Molten Salt Reactors," Annals of Nuclear Energy 35, 314-322 (2008).

18. I. C. Gauld, G. Radulescu, G. Ilas, B. D. Murphy, M. L. Williams, and D. Wiarda, "Isotopic Depletion and Decay methods and Analysis Capabilities in SCALE," Nuclear Technology 174, (2011).

19. B. T. Rearden and M. A. Jessee, eds., SCALE Code System, ORNL/TM-2005/39, Version 6.2, Oak Ridge National Laboratory, Oak Ridge, Tennessee, June 2016. Available from Radiation Safety Information Computational Center at Oak Ridge National Laboratory as CCC-834. 
20. G. M. Tartal, "Summary of June 7-8, 2016, Department of Energy and Nuclear Regulatory Commission Co-Hosted Workshop on Advanced Non-Light Water Reactors," July 7, 2016. http://www.nrc.gov/docs/ML1618/ML16188A226.pdf. Accessed December 18, 2016. 